\title{
Short-Term and Long-Term Entrepreneurial Intention Comparison between Pakistan and Vietnam
}

\author{
Asim Nasar ${ }^{1, *}$, Suzilawati Kamarudin ${ }^{1,2}$, Adriana Mohd Rizal ${ }^{1}$, Vu Thi Bich Ngoc ${ }^{3}$ and \\ Samar Mohammad Shoaib ${ }^{4}$ \\ 1 Azman Hashim International Business School, Universiti Teknologi Malaysia, Kuala Lumpur 54100, \\ Malaysia; s.kamarudin@ubt.edu.sa (S.K.); adriana.kl@utm.my (A.M.R.) \\ 2 College of Business Administration, University of Business and Technology, Jeddah 21448, Kingdom of \\ Saudi Arabia \\ 3 Faculty of Mathematical Economics, National Economics University, Hanoi 11616, Vietnam; \\ ngocvu@neu.edu.vn \\ 4 Deanship of Scientific Research, University of Business and Technology, Jeddah 21448, Kingdom of Saudi \\ Arabia; s.shoaib@ubt.edu.sa \\ * Correspondence: aasimnasar@gmail.com
}

Received: 18 September 2019; Accepted: 13 November 2019; Published: 20 November 2019

\begin{abstract}
This study's purpose is to measure entrepreneurial intention in near and distant time scales using temporal construal theory and the theory of planned behavior. It examines new patterns to measure individual intentions to become an entrepreneur, which are classified into short-term entrepreneurial intention and long-term entrepreneurial intention, using a two-country study. A cross-sectional study of 447 university students in business and non-business disciplines from Pakistan and Vietnam was conducted. Structural equation modeling and the partial least squares model were used to present path modeling and multigroup analysis. The proposed model for entrepreneurial temporal intention was tested using the theory of planned behavior dimensions with the potential temporal spectrum of short-term and long-term intentions. The results indicated differences in individual entrepreneurial temporal intentions across the two lower middle-income countries. The findings depict that short-term entrepreneurial intention significantly mediates the effect between the theory of planned behavior dimensions and long-term entrepreneurial intention, and more specifically, that long-term entrepreneurial intention is higher than short-term entrepreneurial intention in both countries. In comparison, the theory of planned behavior dimensions indicated more power in Pakistan's student sample. This paper presents a new perspective to compare differences in entrepreneurial intention with time fluctuation and thus provides support in identifying potential nascent entrepreneurs based on their psychological distance in thinking and primitive action.
\end{abstract}

Keywords: temporal intention; entrepreneurship; theory of planned behavior; country

\section{Introduction}

Entrepreneurship is considered to be a significant component for social and economic growth, especially for developing nations [1-3]. The literature has confirmed that entrepreneurial activity is extremely important for economic uplifting, societal well-being, and sustainability [4-6]. In the modern era, entrepreneurship has a huge potential to support economic development, overcome unemployment issues, bring innovation in the business process, and establish small and medium enterprises [7-11]. As per the Global Entrepreneurship Monitor report (2017), people from developing countries have strong intentions to become entrepreneurs; $30 \%$ as compared to developed countries with $25 \%$ [12]. Previous studies have confirmed that intention is an important predictor to determine 
behavioral actions. Entrepreneurial intention plays a significant role in driving the behavioral actions for a starting business [13]. At first, entrepreneurs need to figure out the steps involved in starting a new business and deal with the factors influencing planned behavior [14]. It is important to understand the process involved in the formation of entrepreneurial intention [15-17]. The question raised here is whether the formation of intention is a time-dependent process or not. Fayolle and Liñán raised an important point to test entrepreneurial intention models with new theories, methods, and mediating variables for better understanding the process of developing entrepreneurial intention [18]. Ajzen's theory of planned behavior (TPB) has been widely used to assess the entrepreneurial intentions of university students [19-22]. Yet, TPB does not explicitly measure the process involved in the formation of entrepreneurial intention with respect to a time scale. Ajzen mentioned in an interview (conducted in 2019), regarding the implication of entrepreneurial research, that "whether the intention to perform a behavior 'in the future' versus 'in the next six months' makes an appreciable difference is an empirical question that has no a priori answer" [23]. Thus, the formation of entrepreneurial intention is a time-taking process and is influenced by direct and indirect effects of TPB antecedents. Several studies have examined entrepreneurial intention and its antecedents using integrated models and theories; however, an individual's intent to become an entrepreneur has been less focused on regarding time scale $[4,24,25]$.

In fact, people from developing countries have the perception of a large number of business opportunities in their country, thus it is important to understand their perception and willingness to be part of entrepreneurial activity using a time scale for measuring entrepreneurial intention [24-26]. The published research studies also highlighted that an individual's perception or intent has a time-dependent effect in terms of achieving possible outcomes [22,27]. The authors raised an argument for using a time scale to measure entrepreneurial intention, to determine whether it falls in the near or distant future $[4,17,25,26,28]$.

The research studies conducted to measure entrepreneurial intent used a generic timeframe $[29,30]$ and combined the near-future and distant-future measures of entrepreneurial intention $[13,19,31]$. The multifarious nature of intention works as a predictor of behavioral outcomes [17,32]. An individual's desire to perform actions in the distant future provides a strong base to make decisions, which are less influenced by the feasibility of doing so [33,34]. It is anticipated that desirability contains more value in terms of making informed decisions for the distant future in comparison with the near future. Many researchers have investigated whether the decision-making process is aligned with the construct of intentions [29,35-38]. It is argued that behavioral outcomes, either perceived or actual, for the near and distant future largely depend on the individual responses regarding entrepreneurial intention. The distant future is construed on a higher level than near-future activities [39]. However, the differences between perceived and actual behavioral outcomes have been less determined by researchers considering the near and distant future for entrepreneurial intention.

This study follows a time-bound approach to address the theoretical gap by measuring entrepreneurial intention, integrating the TPB and temporal construal theory (TCT). The study objective is to measure the direct and indirect influence of TPB dimensions (attitude, subjective norms, and perceived behavior control) on short-term and long-term entrepreneurial intention. The assumption made here is that short-term intent mediates the relationship between TPB dimensions and long-term intent. Hence, we also explored subjective norms and their direct effect on attitude and perceived behavior control and indirect effect on short-term and long-term entrepreneurial intention. University business students are considered in the sample from Pakistan and Vietnam. Pakistan and Vietnam face similar challenges in the development of entrepreneurial activities. As per the Global Entrepreneurship Monitor report (2018), Vietnam is still at the low level of $0.6 \%$ in terms of business start-up rate and faces financial and educational challenges [40]. As per the Global Entrepreneurship Index report (2017), Pakistan is facing challenges in improving start-up skills and risk acceptance in terms of introducing ideas in the market [41]. This study selected Pakistan and Vietnam because of 
the minor differences in their economies and similarities in challenges to become stable in growth and development.

This study contributes in two ways with reference to addressing the call for integrating theories with entrepreneurial intention models and using advanced methodology [22]. First, it integrates TCT and TPB in one model for better understanding of temporal construal for intention in entrepreneurship research. It compares the differences in entrepreneurial intention with time fluctuation and thus provides support in identifying potential nascent entrepreneurs based on their psychological distance in thinking and primitive action. This improves the level of understanding for academicians, policy makers, and concerned authorities to reevaluate entrepreneurial models, which should be based on psychological temporal construal. Second, this study used structural equation modeling as a robust analytical approach to test and validate the model.

Moving on, this paper is structured as follows: First, TPB and TCT are discussed as the underpinning theories in this study. The second section is related to theoretical justification for study variables and the development of hypotheses. After that, the study sample, data collection procedures, measurements, and methods are described. The subsequent section covers the results, interpretation, and discussion. The last section ends with the implications of the study, limitations, and conclusions.

\section{Theoretical Background}

\subsection{Temporal Construal Theory}

TCT is the concept of pre-planning or planning for the future for certain situations. It shows the change in behavior towards decision-making for future events, giving priority to distant-future events and showing less interest in near-future events [42]. People's responses towards future events come in the form of thinking about temporal distance, in which they change their minds with respect to a particular event. When someone has a greater temporal distance, there is a high probability that the person is thinking with limited abstract features of particular events. However, when a person thinks in terms of minor temporal distance, it brings concrete action, which leads to possible actions in the distant future. In this regard, there are two levels of construal: high and low. At first, high-level construal allows people to think more abstractly, which covers the big picture of the particular event and is less focused on the minor details. It brings the overall general picture of the future event, which gives a general idea on the future upcoming situation. Secondly, low-level construal brings more attention towards the current situation or present movement, which is linked to the psychological proximity $[4,39,43]$.

This theoretical construct defines that an entrepreneur or businessperson will always opt for proper construal planning for the distant future to ensure its sustainability. It takes more potential and intentions to plan a distant temporal trip than a near one $[4,33,34,39]$. When an individual thinks more precisely and concretely about an event, focus towards minor details persists [44,45]. It is difficult to identify nascent entrepreneurs at an early stage of their career and education. Each individual will have different psychological proximity to showcase their entrepreneurial spirit and contribute to economic growth. It is clear that not all individuals will have the intention to become an entrepreneur in the near future, since they need some time to make up their mind and execute the action in the distant future. With regards to the psychological proximity reason, it is vital to identify and examine potential entrepreneurs based on their near- and distant-future intent. An individual with a high level of intention is a precursor for the activities that happen in the future via entrepreneurship in the region $[21,24,25,27,46-50]$.

There is an argument established in behavioral economic and decision-making studies for using TCT for better prediction of an individual's perception about outcomes and expected behavior within a time scale [44,51]. Application of TCT in entrepreneurship studies has hardly been addressed by researchers, yet the time scale for intent to be an entrepreneur with self-efficacy indicators has proven its validity and generalizability [2]. Previous research supports the argument of using TCT 
for the refinement of intention models and considering TPB dimensions as predictors to develop the entrepreneurial intention on a time scale. Another argument is developed for the use of TCT; that is, when someone is thinking of becoming an entrepreneur, positive beliefs come across that lead towards the formation of entrepreneurial intention. Thereafter, when someone plans to execute a business idea, confrontation may occur that is linked with negative beliefs regarding the difficulty of performing a behavior for entrepreneurial activity [23]. However, this situation may lead to forgetting time-bound intentions. In conquering this, the use of a time scale for stating entrepreneurial intentions can help in overcoming the challenges for the execution of intentions, with strong follow-up regarding how, where, and when they will execute their intentions to be an entrepreneur and start a business. Yet, temporal construal of entrepreneurial intention should be extended to a short- and long-term spectrum followed by the behavior of an individual in order to act towards the business concept, which aligns with the TPB dimensions [52].

The literature suggests that an individual performing an action may be linked with the different levels of abstraction; so far, TCT has joined the low level of abstraction with the near future and the high level of abstraction with the distant future $[34,38,49,53]$. Alongside that, TCT characterizes the psychological condition of individuals as identifiable with the occasion at the low-level construal understanding when their points of view are subordinate. Be that as it may, a significant level of interpretation will set the bearings or characterize the way in which they will proceed forward later on. The use of TCT with entrepreneurial intention shows the distinction in singular musings at the present and future time identified with the entrepreneurial activity expected to be performed. Utilizing TCT puts the primary spotlight on the perspective dependent on the temporal distance between the time of posing an inquiry and the time of conducting activities. However, this study considers intention to become an entrepreneur at two points of time, using short-term and long-term intention [2,9,27,32]. Therefore, this study proposes the following hypothesis based on the applicability of TCT in measuring entrepreneurial intention.

H1. Long-term entrepreneurial intention is higher than short-term entrepreneurial intention.

\subsection{Theory of Planned Behavior}

In social psychology and cognitive approaches, TPB posits that intention predicts individual behavior, and further indicates the level of effort rendered by an individual to perform planned actions [54,55]. Ajzen raised a valid point that people incline to make plans and develop an intention before performing any action. TPB is a widely accepted framework that measures intentions $[1,52,54,56-58]$. This theory has been applied in many disciplines such as health, social sciences, medical, and entrepreneurial activity [56,59-61]. There are several studies that have measured the validity and application of the theory in different cultural contexts $[2,22,28]$. TPB was used to explain a clear process of entrepreneurial activity that covers the individual's efforts to be part of entrepreneurship based on the three dimensions to predict behavioral intention [21,54]. TPB and entrepreneurial event models have been widely used to assess entrepreneurial intention and to provide support in understanding the process of entrepreneurial activity [17]. However, the applicability of TPB is well-documented in entrepreneurship studies $[3,6,9,29]$. Several authors refer to TPB due to its coherent framework, enhancing better understanding for measuring entrepreneurial intention $[18,22,59]$. In TPB, behavioral intention is measured by three antecedents called attitude, subjective norms, and perceived behavior control.

Attitude is defined as an individual way of thinking or feeling or an opinion about entrepreneurial activity $[9,20]$. Attitude is also explained by individual preferences and associated with advantages or disadvantages. Published studies have measured attitude as an influential factor, which covers the desirability of becoming an entrepreneur [62]. In previous studies, attitude has a positive relationship with entrepreneurial intention $[20,63,64]$; however, attitude in relation to short-term and long-term intention is less addressed [2]. 
Subjective norms relate to the influence of society on individual intention, behavior or both. An individual depends on the endorsement or dissatisfaction from a group of friends (companions, family, close relations) so as to step up to the plate for business arrangements [21,65]. There are inconsistencies in the published results regarding a positive relationship between subjective norms and entrepreneurial intention $[17,19,25]$; however, it is logical to test the relationship between subjective norms and entrepreneurial temporal intention, as the people who come into the social circle of an individual play a vital role to inform their decision to become an entrepreneur [57].

Perceived behavior control refers to a belief in which an individual executes planned behavior and builds a perception of having control over it [54]. Some studies defined this as the ease or difficulty of performing a behavior for entrepreneurial activity $[34,60,66]$. Published studies have confirmed the positive relationship between perceived behavior control and entrepreneurial intention in cross-cultural comparative analysis $[9,17,20]$.

A meta-analysis test approach is used to assess the commonalities between two models, the TPB and entrepreneurial event, yet a mixed model technique is also performed to measure attitude, subjective norms, and perceived behavior control from the TPB, and perceived entrepreneurial self-efficacy in line with perceived desirability and feasibility from the entrepreneurial event model $[28,67]$. Longitudinal studies have assessed the high growth and lifestyle with entrepreneurial intention, in which the same measures were used at different points of time $[45,46]$. Considering the established literature of TPB, the following hypotheses are proposed:

H2. Attitude has a positive effect on short-term entrepreneurial intention.

H3. Subjective norms have a positive effect on short-term entrepreneurial intention.

H4. Perceived behavior control has a positive effect on short-term entrepreneurial intention.

H5. Attitude has a positive effect on long-term entrepreneurial intention.

H6. Subjective norms have a positive effect on long-term entrepreneurial intention.

H7. Perceived behavior control has a positive effect on long-term entrepreneurial intention.

\subsection{Interrelation between TPB Dimensions (Attitude, Subjective Norms, and Perceived Behavior Control)}

There are inconsistent findings related to subjective norms' influence on behavioral intention. Some research studies have mentioned that subjective norms do matter and have direct influence on intentions. Thus, some argue that subjective norms have direct and indirect influences in the formation of an intention, depending on the basis of contextual factors [21]. In conquering this, Linan and Chen estimated the direct influence of subjective norms in the formation of positive and negative attitudes. Nonetheless, another argument is that subjective norms influence perceived behavior control [55]. This argument is developed based on a theoretical underpinning in which a social network, comprised of friends, peers, and parents, may contribute to changing attitudes and perceived behavior control [22]. There was an assumption made on testing subjective norms with attitude and perceived behavior control. This is justifiable that subjective norms are linked to culture; if it allows, then an individual would be inclined toward entrepreneurial activities regardless of the size of the business setup $[21,68]$. In support of this, it may be argued that social and cultural support create a pathway to develop higher intention for starting a business [59]. A TPB description of shared values in a culture creates an impact on performing actions with consent from the circle of influence. Etzioni raised the point that culture provides support to legitimize the process for entrepreneurial activities [69]. Subjective norms imitate the perceived pressure from the people that are close to an individual, which may have a stronger influence on starting a business [31,34,57]. It develops a supportive argument that subjective norms have stronger and direct influence on attitude and perceived behavior control, and indirect influence on intention in a collectivist culture as compared to an individualistic culture [21]. TPB dimensions have been measured with entrepreneurial intention; however, the interrelation of these may not be 
problematic. In previous studies, subjective norms have been closely associated with the approval of "reference people" and "motives to comply" for an individual [70]. Several studies identified subjective norms and motives to comply as having a significant relationship with entrepreneurial intention $[21,71,72]$. However, subjective norms have been shown to be nonsignificant $[17,19]$. It would be appropriate to measure the direct and indirect influence of subjective norms on attitude, perceived behavior control, and entrepreneurial temporal intention to clarify their relative significance. Thus, the well-established argument given supports this study to propose the following hypotheses.

H8. Subjective norms have a positive effect on attitude.

H9. Subjective norms have a positive effect on perceived behavior control.

H10. Attitude has a positive effect on perceived behavior control.

\subsection{Integration of TCT and TPB}

The origin of the word entrepreneur is "to undertake or do something", which belongs to the activity of a planned behavior studied by social psychologists [73]. In previous studies, researchers paid attention to linking attitude and behavior, yet social psychology studies indicated the inconsistency in the theory and mentioned the importance of intention, which plays a vital role in originating behavioral actions $[15,52,54,57,58,74]$. In order to develop the understanding, several studies highlighted the determinants of entrepreneurial intention via theoretical frameworks and models to explain the entrepreneurial process and the intention of an individual who wants to become an entrepreneur $[15,16,54,75-77]$. The entrepreneurial event model is used in several studies, which assume that "the greatest reason for the creation of an entrepreneurial event seems to be a change in an individual's life path, especially in a negative direction" [77]. This model is related to individual behavioral actions, which increase as per the individual's propensity to act, perceived desirability, and feasibility [75]. The inclination to act relates to the individual demeanor to react to a chance, coordinated with the inward locus of control [78]. Seeing an attractive quality mirrors the individual's possibility towards beginning a business and secures their desire to carry out certain activities to accomplish it. Seeing achievability demonstrates the person's impression of future conditions and reasonableness of shaping another business adventure [75]. This model is additionally lined up with the individual office or individual capacity to carry out certain conducts $[79,80]$. In any case, the entrepreneurial event model features the fundamentals that make discernments in accordance with the influence of ethnicity, background, and experiences, which pass through from feasibility and desirability.

An individual's intention to start a business is a target behavior, which is defined by different entrepreneurial models using Ajzen's TPB alignment with regional and demographic control variables $[4,15,35,81]$. TPB dimensions play a significant role in driving intention, which expresses the individual ability and confidence to perform entrepreneurial activities [75]. The attitude may be positive or negative, which depends on the individual intent to become an entrepreneur or not. Attitude shows a positive relationship with entrepreneurial intention [82-84], yet it has not been tested with different time spectra. Subjective norms cover the influence of people, peers, family, and other close-knit relations on the individual's intent to become an entrepreneur or not. Subjective norms also play an integral role in driving attitude and perceived behavior control, which leads towards building a high level of abstraction for entrepreneurial intention $[31,59,85]$. Such norms may vary from culture to culture $[19,51,81]$, and are yet to be confirmed with temporal construal. Perceived behavior control indicates the individual belief about the ease or difficulty of executing the planned behavior to become an entrepreneur or not. It may also show differences considering the gender, ability, confidence, or other environmental influences, so for near- or distant-future behavioral intention, more investigation is required [27].

Consequently, this study will investigate the mediation effect of short-term entrepreneurial intention between TPB dimensions and long-term entrepreneurial intention, along with the indirect 
effects of subjective norms, passing through from attitude and perceived behavior control in a sequence, resulting in the following hypotheses:

\subsubsection{Attitude Mediation Effect}

H11. Attitude mediates the relationship between subjective norms and short-term entrepreneurial intention.

H12. Attitude mediates the relationship between subjective norms and long-term entrepreneurial intention.

H13. Attitude and short-term entrepreneurial intention sequentially mediate the relationship between subjective norms and long-term entrepreneurial intention.

H14. Attitude mediates the relationship between subjective norms and perceived behavior control.

H15. Attitude and perceived behavior control sequentially mediate the relationship between subjective norms and short-term entrepreneurial intention.

H16. Attitude and perceived behavior control sequentially mediate the relationship between subjective norms and long-term entrepreneurial intention.

H17. Attitude, perceived behavior control and short-term entrepreneurial intention sequentially mediate the relationship between subjective norms and long-term entrepreneurial intention.

\subsubsection{Perceived Behavior Control Mediation Effect}

H18. Perceived behavior control mediates the relationship between subjective norms and short-term entrepreneurial intention.

H19. Perceived behavior control mediates the relationship between subjective norms and long-term entrepreneurial intention.

H20. Perceived behavior control and short-term entrepreneurial intention sequentially mediate the relationship between subjective norms and long-term entrepreneurial intention.

H21. Perceived behavior control mediates the relationship between attitude and short-term entrepreneurial intention.

H22. Perceived behavior control mediates the relationship between attitude and long-term entrepreneurial intention.

H23. Perceived behavior control and short-term entrepreneurial intention mediate the relationship between attitude and long-term entrepreneurial intention.

\subsubsection{Short-Term Entrepreneurial Intention Mediation Effect}

H24. Short-term entrepreneurial intention mediates the relationship between attitude and long-term entrepreneurial intention.

H25. Short-term entrepreneurial intention mediates the relationship between subjective norms and long-term entrepreneurial intention.

H26. Short-term entrepreneurial intention mediates the relationship between perceived behavior control and long-term entrepreneurial intention.

The Global Competitiveness report categorized countries into three groups: factor-driven, efficiency-driven, and innovation-driven. Factor-driven countries largely depend on agriculture, efficiency-driven countries rely on the small and medium sectors, and innovation-driven countries are related with advancements in research, technology, and modern forms of production. In this 
study, Pakistan and Vietnam belong to the group of factor-driven economies. In previous studies, entrepreneurial intention was investigated with respect to culture, demographics, and country context $[2,9,86]$. TPB dimensions induce differences in the score of entrepreneurial intention considering the differences in the environment, economic conditions, and development practices $[29,87]$. Thereby, the following hypothesis is proposed:

H27. There is an impact difference of TPB dimensions on short-term and long-term entrepreneurial intention between Pakistan and Vietnam.

\subsection{Study Framework}

The study framework, based on the abovementioned literature review on TPB and TCT for entrepreneurial intention, is proposed in Figure 1. The integration of both theories can better support the understanding of the short-term and long-term intent to be an entrepreneur. In this framework, TPB dimensions exert direct influence on entrepreneurial temporal intention. Direct paths are mentioned in hypotheses H1 to H10. Further, attitude, perceived behavior control, and short-term intent are assessed in terms of medication effect between subjective norms and long-term intent, as highlighted with gray color. Indirect paths are specified with dashed lines for hypotheses H11 to H26.

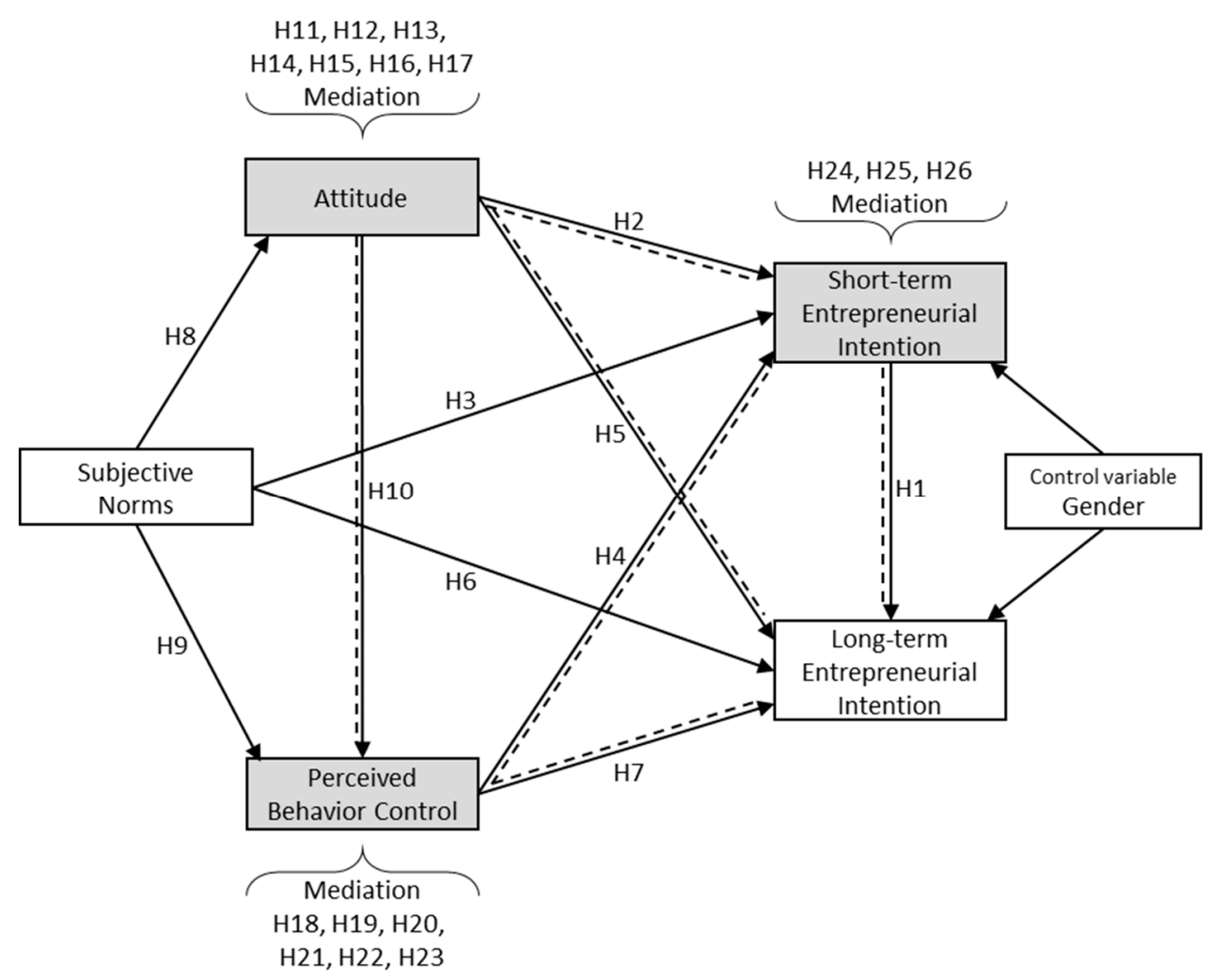

Figure 1. Model for entrepreneurial temporal intention (authors' own).

\section{Methods}

Two data sets were collected from Pakistan and Vietnam in order to measure unbiased short-term and long-term entrepreneurial intention. Considering the reason, subjects are current students of business and non-business degree programs from universities in multiple cities. Previous research studies indicated the positive effect of business and entrepreneurial education on intention [4]; so far, the inclusion of students in the sample provides a strong basis to measure the model and generalizability of results. Data were collected from June 2019 to August 2019 using the previously used and confirmed measures for intention. The items used in the final questionnaire were translated into the native 
language of the participants (i.e., Urdu for Pakistan and Vietnamese for Vietnam), to facilitate a better understanding of the subjects, with forward and backward translations performed by experts to ensure the equivalence of the test questionnaire [50]. To confirm the validity of the items, the authors used the published questionnaire; however, to ensure reliability, a pre-investigation test was performed by analyzing the responses from a sample of 30 students, and as a result, some of the items were simplified and deleted from the survey [50].

\subsection{Participants and Procedure}

The analysis was performed using a sample of 447 participants, in which 243 participants were from Pakistan and 204 from Vietnam. The statistical power criterion was used to select the minimum sample by using G*Power 3.1 software [88] (manufacturer: Mannheim, Germany), as suggested by Hair et al. [50]. The research model has three predictors, thereby an effect size of 0.15 and power of 0.95 were taken. As per this criterion, the required minimum sample size was 89 for each country. Therefore, the selected sample size for this study was above the minimum requirement. The appropriate selection of sample size as per the mentioned criteria has proved an advantage in the literature in order to save time and for budget limitation. The convenience sampling technique was employed to gather the data, which has been employed in several entrepreneurial research studies for multi-country comparison $[83,89]$. Electronic and paper form questionnaires were circulated to gather the data during classes. Only volunteer participation was taken to fill the survey forms. For both countries, electronic forms were administrated in consultation with lecturers and passed on to WhatsApp groups created by them. In total, 384 (86\%) electronic and $63(14 \%)$ paper forms were received without missing values for all the items. The total sample comprised of $275(61.5 \%)$ females and $172(38.5 \%)$ males; 287 business students (64.2\%) and 160 non-business students (35.8\%); 274 entrepreneurship students (61.3\%) and 173 non-entrepreneurship students (38.7\%). Moreover, some of the study participants (187) were working while studying (41.8\%), and some (260) were not working while studying (58.2\%); those whose parents were doing business accounted for $232(51.9 \%)$, and those whose parents were not doing business accounted for 215 (48.1\%). Descriptive statistics are detailed in Tables 1 and 2.

Table 1. Descriptive statistics (values, percent).

\begin{tabular}{cccc}
\hline & $\begin{array}{c}\text { Pakistan } \\
(\boldsymbol{n}=\mathbf{2 4 3})\end{array}$ & $\begin{array}{c}\text { Vietnam } \\
(\boldsymbol{n}=\mathbf{2 0 4})\end{array}$ & $\begin{array}{c}\text { Total Sample } \\
(\boldsymbol{n}=447)\end{array}$ \\
\hline $\begin{array}{c}\text { Gender } \\
\text { Male }\end{array}$ & $111(45.7 \%)$ & $61(29.9 \%)$ & $172(38.5 \%)$ \\
Female & $132(54.3 \%)$ & $143(70.1 \%)$ & $275(61.5 \%)$ \\
Entrepreneurial Network & $158(65.0 \%)$ & $111(54.4 \%)$ & $269(60.2 \%)$ \\
Yes & $85(35.0 \%)$ & $93(45.6 \%)$ & $178(39.8 \%)$ \\
No & $162(66.7 \%)$ & $125(61.3 \%)$ & $287(64.2 \%)$ \\
Studying Business & $81(33.3 \%)$ & $79(38.7 \%)$ & $160(35.8 \%)$ \\
Yes & & & \\
No & $107(44.0 \%)$ & $167(81.9 \%)$ & $274(61.3 \%)$ \\
Studied & $136(56.0 \%)$ & $37(18.1 \%)$ & $173(38.7 \%)$ \\
Entrepreneurship & & & \\
Yes & $134(55.1 \%)$ & $98(48.0 \%)$ & $232(51.9 \%)$ \\
No & $109(44.9 \%)$ & $106(52.0 \%)$ & $215(48.1 \%)$ \\
Yes Business & & & \\
No & $53(21.8 \%)$ & $134(65.7 \%)$ & $187(41.8 \%)$ \\
Parents Doing $)$ & $70(34.3 \%)$ & $260(58.2 \%)$ \\
\hline Yes & $190(78.2 \%)$ &
\end{tabular}


Table 2. Mean and standard deviation (SD).

\begin{tabular}{|c|c|c|c|c|c|c|c|c|}
\hline & \multicolumn{4}{|c|}{ Short-Term Entrepreneurial Intention } & \multicolumn{4}{|c|}{ Long-Term Entrepreneurial Intention } \\
\hline & \multicolumn{2}{|c|}{ Pakistan } & \multicolumn{2}{|c|}{ Vietnam } & \multicolumn{2}{|c|}{ Pakistan } & \multicolumn{2}{|c|}{ Vietnam } \\
\hline & Mean & SD & Mean & SD & Mean & SD & Mean & SD \\
\hline \multicolumn{9}{|l|}{ Gender } \\
\hline Male & 5.96 & 1.35 & 4.07 & 1.66 & 5.99 & 1.31 & 4.58 & 1.77 \\
\hline Female & 4.57 & 1.79 & 3.61 & 1.51 & 4.60 & 1.81 & 3.97 & 1.64 \\
\hline \multicolumn{9}{|c|}{ Entrepreneurial Network } \\
\hline Yes & 5.30 & 1.76 & 3.92 & 1.57 & 5.35 & 1.74 & 4.37 & 1.68 \\
\hline No & 5.03 & 1.71 & 3.54 & 1.56 & 5.02 & 1.73 & 3.89 & 1.70 \\
\hline \multicolumn{9}{|c|}{ Studying Business } \\
\hline Yes & 5.31 & 1.71 & 4.10 & 1.55 & 5.31 & 1.73 & 4.56 & 1.70 \\
\hline No & 5.01 & 1.81 & 3.19 & 1.45 & 5.09 & 1.77 & 3.49 & 1.49 \\
\hline \multicolumn{9}{|c|}{ Studied Entrepreneurship } \\
\hline Yes & 5.08 & 1.79 & 3.87 & 1.55 & 4.99 & 1.81 & 4.23 & 1.69 \\
\hline No & 5.30 & 1.71 & 3.19 & 1.54 & 5.43 & 1.66 & 3.78 & 1.73 \\
\hline \multicolumn{9}{|c|}{ Parents Doing Business } \\
\hline Yes & 4.98 & 1.86 & 3.97 & 1.65 & 5.04 & 1.83 & 4.39 & 1.74 \\
\hline No & 5.49 & 1.56 & 3.54 & 1.47 & 5.48 & 1.59 & 3.93 & 1.65 \\
\hline \multicolumn{9}{|c|}{ Working somewhere } \\
\hline Yes & 5.29 & 1.66 & 3.60 & 1.56 & 5.27 & 1.61 & 4.10 & 1.68 \\
\hline No & 5.18 & 1.77 & 4.03 & 1.55 & 5.22 & 1.78 & 4.25 & 1.75 \\
\hline
\end{tabular}

\subsection{Measures of Entrepreneurial Intention}

The entrepreneurial intention measures were derived from the published literature and had reported high Cronbach's $\alpha$ scores and validity in several study settings. The intention tool indicated a Cronbach's $\alpha$ of 0.824 for short-term entrepreneurial intention and 0.851 for long-term entrepreneurial intention, which is consistent with the literature $[13,22,25,56]$. Many research scholars have measured intention using a single binary to six-point Likert scale $[3,4,85]$ at a single point of time. However, intention was less likely to be measured at different time intervals $[13,19,56,85]$. Four items were used to measure the time-bound intent of an individual, which were classified into short-term entrepreneurial intention and long-term entrepreneurial intention, as well as all other time periods covered between the set of questions [32,39]. Two items were identified for the short-term entrepreneurial intention as already used in the literature, "I am determined to create a firm in the future" [22] and "After my graduation, I intend to start my own company or business" $[2,13,27,56]$, and similarly, two items for long-term entrepreneurial intention, "I have very serious thoughts about starting my own firm" [22] and "To what extent do you intend to someday start your own company or business?" [13,27,56]. Further, these four items were rephrased properly by replacing "firm" with "company", and "start" with "create" in order to ensure the word similarity in the tool. One item from long-term entrepreneurial intention "To what extent do you intend to someday start your own company or business?" was rephrased into the self-administered question "I intend someday to start my own company or business". Six items were used to measure attitude, adapted from [22]. Later, one item of attitude was deleted because of a weak loading factor. Subjective norms and perceived behavior control were measured using three and six items, respectively, adapted from Liñán and Chen [43]. TPB questions were assessed on a seven-point Likert scale from 1-strongly disagree to 7-strongly agree. The construct, item loadings, and discriminant validity are shown in Tables 3 and 4. 
Table 3. Measurement model results.

\begin{tabular}{|c|c|c|c|c|c|c|c|c|c|c|}
\hline \multirow[b]{2}{*}{ Construct } & \multirow[b]{2}{*}{ Loadings } & \multicolumn{3}{|c|}{ Full Sample } & \multicolumn{3}{|c|}{ Pakistan } & \multicolumn{3}{|c|}{ Vietnam } \\
\hline & & $\alpha$ & CR & AVE & $\alpha$ & CR & AVE & $\alpha$ & CR & AVE \\
\hline Attitude (ATT) & & 0.856 & 0.896 & 0.634 & 0.837 & 0.884 & 0.605 & 0.864 & 0.903 & 0.652 \\
\hline "ATT1. A career as an entrepreneur is attractive to me" & 0.773 & & & & & & & & & \\
\hline "ATT2. If I had the opportunity and resources, I would like to start a company" & 0.783 & & & & & & & & & \\
\hline "ATT3. Being an entrepreneur would entail great satisfaction for me" & 0.840 & & & & & & & & & \\
\hline "ATT4. Among various options, I would rather be an entrepreneur" & 0.832 & & & & & & & & & \\
\hline "ATT5. I believe that if I will start my business, I will certainly succeed" & 0.752 & & & & & & & & & \\
\hline Subjective Norms (SN) & & 0.836 & 0.901 & 0.753 & 0.779 & 0.870 & 0.691 & 0.858 & 0.913 & 0.778 \\
\hline "SN1. I believe that people think I should pursue a career as an entrepreneur" & 0.866 & & & & & & & & & \\
\hline "SN2. My friends see entrepreneurship as a logical choice for me" & 0.893 & & & & & & & & & \\
\hline "SN3. My parents are positively oriented toward a career as an entrepreneur" & 0.844 & & & & & & & & & \\
\hline Perceived Behavior Control (PBC) & & 0.916 & 0.935 & 0.704 & 0.881 & 0.909 & 0.626 & 0.918 & 0.936 & 0.709 \\
\hline "PBC1. To start a company and keep it working would be easy for me" & 0.807 & & & & & & & & & \\
\hline "PBC2. I am prepared to start a viable company" & 0.841 & & & & & & & & & \\
\hline "PBC3. I can control the creation process of a new company" & 0.856 & & & & & & & & & \\
\hline "PBC4. I know the necessary practical details to start a company" & 0.823 & & & & & & & & & \\
\hline "PBC5. I know how to develop an entrepreneurial project" & 0.861 & & & & & & & & & \\
\hline "PBC6. If I tried to start a company, I would have a high probability of succeeding" & 0.847 & & & & & & & & & \\
\hline Short-Term Entrepreneurial Intention (STEI) & & 0.824 & 0.919 & 0.850 & 0.815 & 0.915 & 0.844 & 0.785 & 0.902 & 0.822 \\
\hline "STEI1. I am determined to create a company in the future" & 0.925 & & & & & & & & & \\
\hline "STEI2. After my graduation, I intend to create my own company or business" & 0.919 & & & & & & & & & \\
\hline Long-Term Entrepreneurial Intention (LTEI) & & 0.851 & 0.931 & 0.870 & 0.822 & 0.918 & 0.849 & 0.863 & 0.936 & 0.879 \\
\hline "LTEI1. I have a very serious thought about starting my own company" & 0.939 & & & & & & & & & \\
\hline "LTEI2. I intend someday to start my own company or business" & 0.927 & & & & & & & & & \\
\hline
\end{tabular}


Table 4. Discriminant validity.

\begin{tabular}{ccccccc}
\hline & ATT & Gender & LTEI & PBC & SN & STEI \\
\hline ATT & 0.797 & & & & & \\
Gender & -0.231 & 1.000 & & & & \\
LTEI & 0.668 & -0.328 & 0.933 & & & \\
PBC & 0.526 & -0.207 & 0.538 & 0.839 & & \\
SN & 0.679 & -0.271 & 0.609 & 0.649 & 0.868 & \\
STEI & 0.740 & -0.326 & 0.822 & 0.590 & 0.687 & 0.922 \\
\hline
\end{tabular}

Note: Diagonal values show the square root of AVE.

\subsection{Control Variable}

A difference in women's and men's perceptions about entrepreneurial intention has been observed in developed and developing countries [47]. A limited number of studies has investigated career preferences between women and men [90]. Entrepreneurship is considered to be for men instead of women based on strong thoughts towards self-employment [91]. As proposed by prior research studies, gender was used as a dummy variable coded 0 for men and 1 for women in this study to see the differences in the career intention [92]. The entrepreneurial intention gap exists between men and women using temporal construal in several countries [27,93].

\subsection{Data Analysis}

Structural equation modeling (SEM) used to test the model using Smart PLS (v3.2.8), a well renowned software package for the partial least squares approach to SEM-based analysis and multigroup analysis [84]. The SEM method provides a wider spectrum in analyzing the mediation direct and indirect effects of latent variables; however, it also measures the strongest and weakest path coefficients of large and complex models $[40,94]$. SEM has been the preferred method in management science studies to assess the model fit information and consistency with data [95]. There are two methods that have been used in SEM (i.e., covariance-based (CB-SEM) and partial least squares (PLS-SEM)); however, the authors used PLS-SEM because it has the ability to identify the complex relationship of constructs, justify theoretical levels, and present relative values of path coefficients [1,24]. This study model is comprised of mediating variables; therefore, the use of PLS-SEM will ensure correct and valid terms for theory validation and will predict the relationship among the variables [5,96,97]. Considering this rationale, the PLS-SEM method is widely considered for examining complex relationships, and the authors examined the TPB dimensions' effect on entrepreneurial intention in the past [9]. PLS gives the advantage of establishing the discriminant validity without any sample limitations [96]. The PLS technique estimated the study model with two steps (i.e., a measurement model (inner) and structural model (outer)) that establish the link among latent variables.

\section{Results}

\subsection{Measurement Model}

In this study, the measurement model comprised the TPB dimensions and entrepreneurial temporal intention with their latent constructs. All the reflective measures were assessed by their reliability test using Cronbach's $\alpha$ value and composite reliability (CR). To measure the convergent validity, the average variance extracted (AVE) was used. The loadings for all the reflective items met the above criterion of threshold value 0.7 , except for one item of attitude, which was deleted (see Table 3) [98]. Reliability was ensured via $\alpha$ values and CR: $\alpha$ values for all the constructs ranged from 0.779 to 0.918 , and $C R$ values ranged from 0.884 to 0.936 . Convergent validity was indicated by AVE values ranging from 0.605 to 0.879 , which are all higher than 0.5 [99]. Discriminant validity is established when the square root of the AVE is higher than the correlation, as mentioned in Table 4 [1]. For the cross-sectional study, the common method of variance performed on Harman's single-factor test indicated a level 
lower than the 50\% threshold, thereby, with no effect on the results [100]. Since all the variance inflation factors depict values less than 5, no multicollinearity exists [101].

\subsection{Structural Model}

PLS-SEM was used to validate the hypothetical model after confirming the measurement model. Bootstrapping with 5000 sub-samples and t-statistic was applied to check the relationship. Path coefficients and coefficients of determination $\left(R^{2}\right)$ were thoroughly explained in the structural model for Pakistan and Vietnam separately (see Figures 2-4, Table 5). Mediation analysis was performed to specify the direct and indirect effects (see Tables 6-8). Multigroup analysis (MGA) was also examined to see the differences in the factors between Pakistan and Vietnam and to check the statistically significant paths between Pakistan's and Vietnam's models [5]. MGA compositional invariance is presented in Tables 9 and 10. The differences in the factors are aligned with observed heterogeneity with no possibility of non-observed heterogeneity, thereby, it is not anticipated to contribute to the specified variables in the model [64].

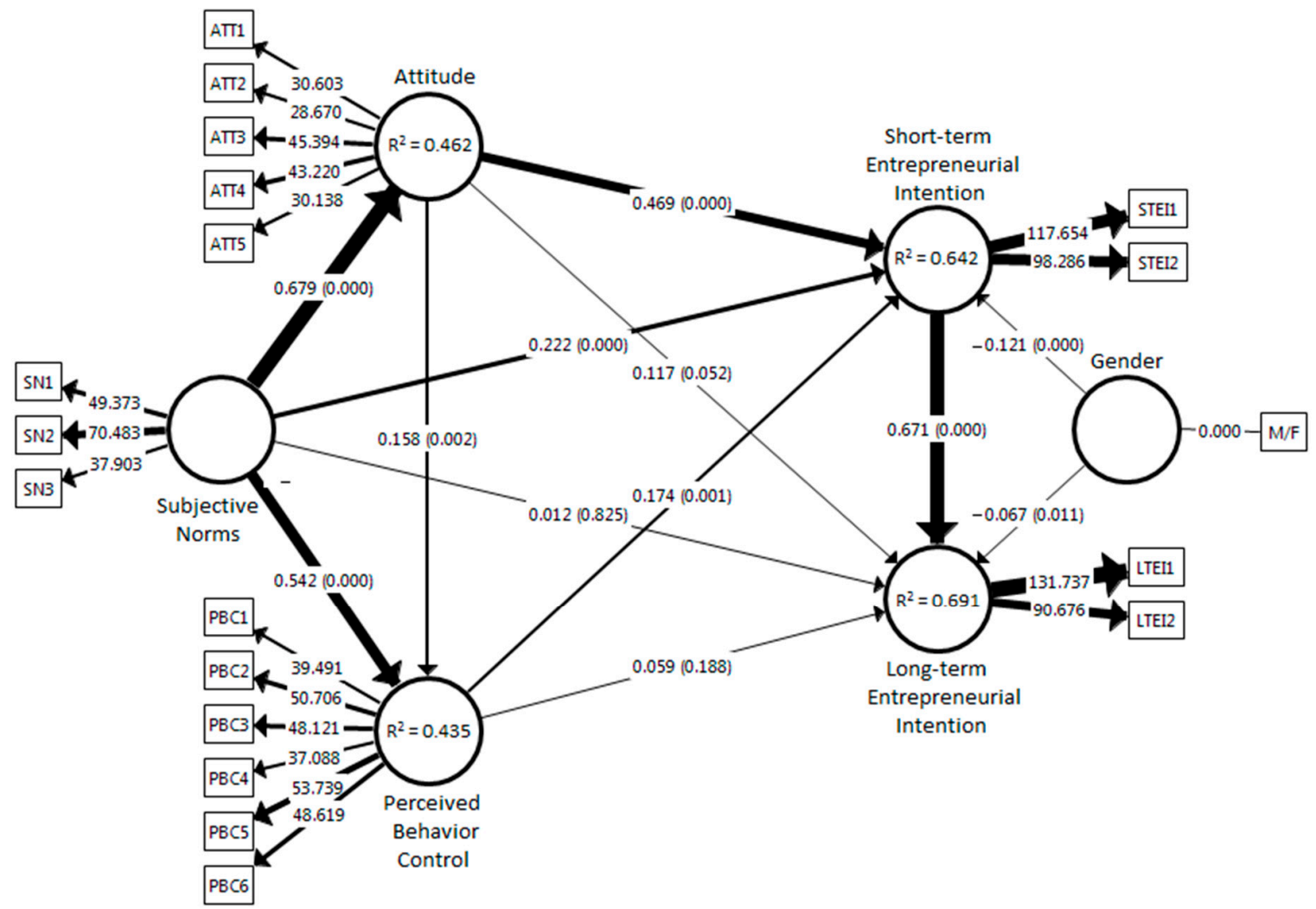

Figure 2. Model for entrepreneurial temporal intention (Pakistan and Vietnam). Source: authors' own. Notes: full samples of Pakistan and Vietnam, using relative values to highlight paths. Path coefficients are indicated on arrow lines and values in brackets indicate significant values. Values in circles indicate R-squares and values with construct items indicate t-values. SmartPLS (v3.2.8) was used to obtain results. $p<0.05 ; p<0.01 ; p<0.001$. 


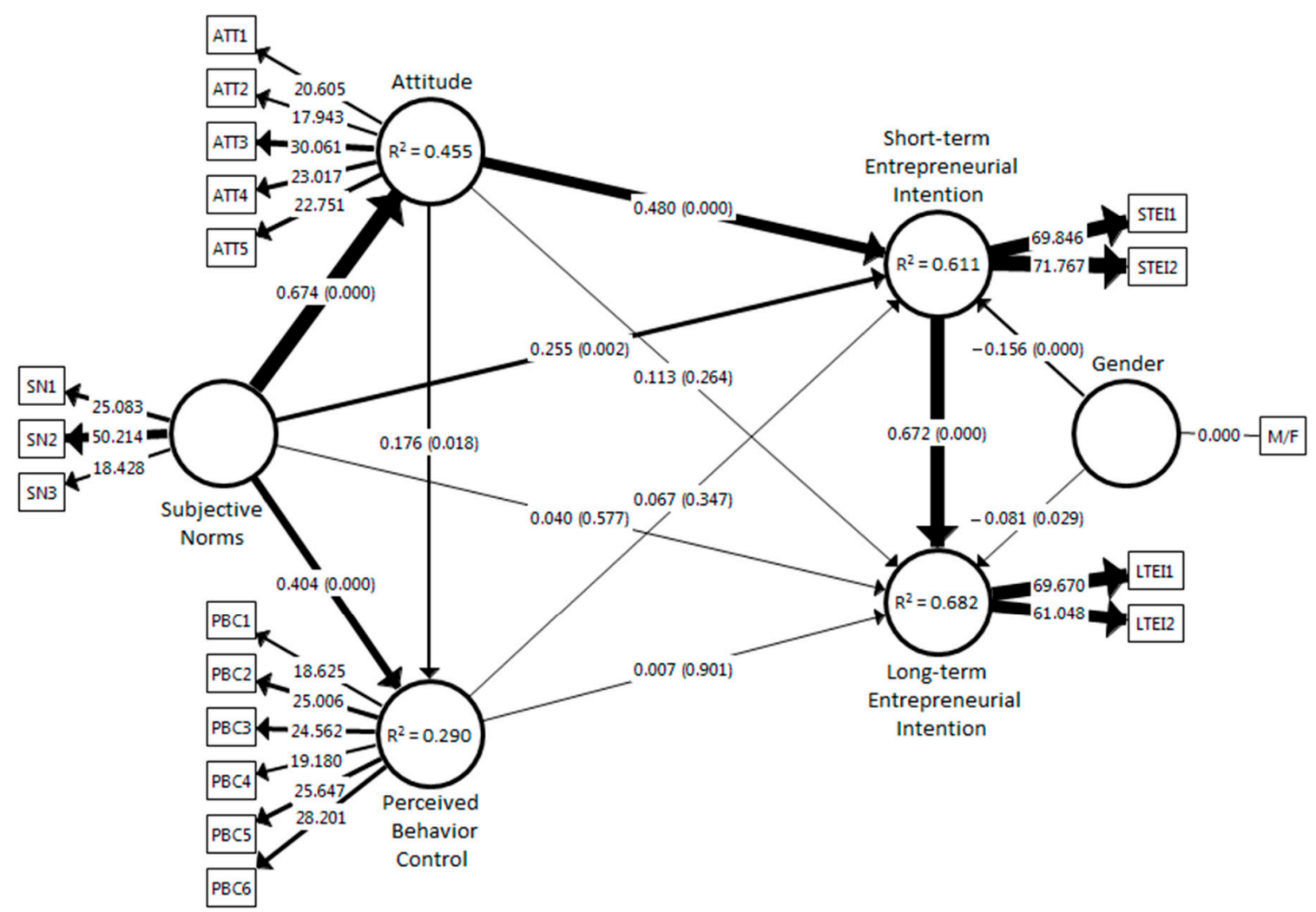

Figure 3. Model for entrepreneurial temporal intention (Pakistan). Source: authors' own. Notes: sample of Pakistan, using relative values to highlight paths. Path coefficients are indicated on arrow lines and values in brackets indicate significant values. Values in circles indicate R-squares and values with construct items indicate t-values. SmartPLS (v3.2.8) was used to obtain results. $p<0.05 ; p<0.01$; $p<0.001$. 


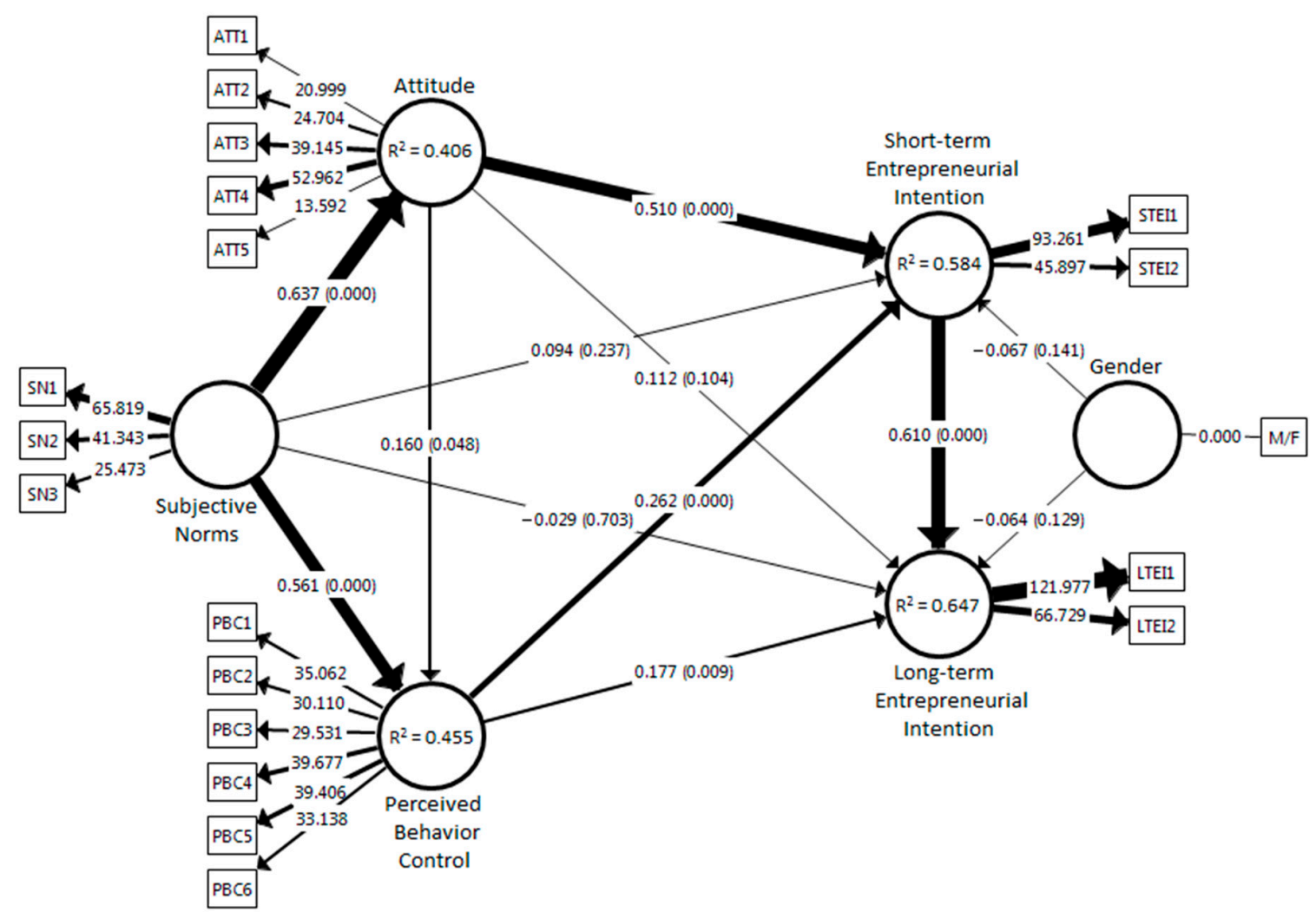

Figure 4. Model for entrepreneurial temporal intention (Vietnam). Source: authors' own. Notes: sample of Vietnam, using relative values to highlight paths. Path coefficients are indicated on arrow lines and values in brackets indicate significant values. Values in circles indicate R-squares and values with construct items indicate t-values. SmartPLS (v3.2.8) was used to obtain results. $p<0.05 ; p<0.01$; $p<0.001$.

\subsection{Hypothesis Testing}

The values extracted from the PLS analysis represent the relationship, significance level, and variance explained $\left(\mathrm{R}^{2}\right)$ for the model [36]. A bootstrapping method was performed with 5000 sub-samples to understand the significance relationship among TPB dimensions, short-term entrepreneurial intention, and long-term entrepreneurial intention for Pakistan and Vietnam separately. The results of the proposed significant and nonsignificant relationships are mentioned in Figures 2-4 and Tables 5-9. Regarding H1, the variance explained for both countries was $\mathrm{R}^{2}=0.642$ for short-term entrepreneurial intention and $\mathrm{R}^{2}=0.691$ for long-term entrepreneurial intention. For the Pakistan student sample, the TPB dimensions together explained $61.1 \%$ and $68.2 \%$ of variance in short-term entrepreneurial intention and long-term entrepreneurial intention, respectively. For the Vietnam student sample, the TPB dimensions together explained $58.4 \%$ and $64.7 \%$ of variance in short-term entrepreneurial intention and long-term entrepreneurial intention, respectively. H1, supported as long-term entrepreneurial intention, is higher than short-term entrepreneurial intention for both countries in combination and separation. The $\mathrm{R}^{2}$ values indicate higher level of intentions for students from Pakistan as compared to Vietnam, which demonstrates more favorable attitudes in the short and long term. Regarding $\mathbf{H} 2$ to $\mathbf{H 7}$, TPB dimensions are positively related to short-term entrepreneurial intention and indicate a nonsignificant level in explaining long-term entrepreneurial intention for both countries. For Pakistan, attitude and subjective norms are positively related to short-term entrepreneurial intention, unlike perceived behavior control, and show a nonsignificant level in explaining long-term entrepreneurial intention. For Vietnam, attitude and perceived behavior control are positively related to short-term entrepreneurial intention, unlike subjective norms, and indicate a nonsignificant level in explaining long-term entrepreneurial intention, except for perceived behavior 
control. Regarding $\mathbf{H 8}$ to $\mathbf{H 1 0}$, subjective norms are positively related to attitude and perceived behavior control, and the same with attitude to perceived behavior control, all together explaining $46.2 \%$ and $43.5 \%$ of variance in attitude and perceived behavior control, respectively, for both countries. Furthermore, subjective norms explained $45.5 \%$ of variance in attitude and $29 \%$ in perceived behavior control for Pakistan, and $40.6 \%$ in attitude and $45.5 \%$ in perceived behavior control for Vietnam. Gender as a control variable was also examined and indicated a significant impact on short-term entrepreneurial intention and long-term entrepreneurial intention for both countries with negative coefficient results; however, gender showed a nonsignificant level in the case of Vietnam separately.

Table 5. Path coefficients-model for entrepreneurial temporal intention.

\begin{tabular}{ccccc}
\hline Relationship & Full Sample & Pakistan & Vietnam & Hypotheses \\
\hline Gender $\rightarrow$ STEI & $-0.121^{* * *}$ & $-0.156^{* * *}$ & -0.067 & Control variable \\
Gender $\rightarrow$ LTEI & $-0.067^{*}$ & $-0.081^{*}$ & -0.064 & Control variable \\
Entrepreneurial Temporal Intention & & & & \\
STEI $\rightarrow$ LTEI & $0.671^{* * *}$ & $0.672^{* * *}$ & $0.61^{* * *}$ & H1 \\
Short-Term Entrepreneurial & & & & \\
Intention & & & & H2 \\
ATT $\rightarrow$ STEI & $0.469^{* * *}$ & $0.48^{* * *}$ & $0.51^{* * *}$ & H3 \\
SN $\rightarrow$ STEI & $0.222^{* * *}$ & $0.255^{* *}$ & 0.094 & H4 \\
PBC $\rightarrow$ STEI & $0.174^{* *}$ & 0.067 & $0.262^{* * *}$ & \\
Intention & & & & H5 \\
ATT $\rightarrow$ LTEI & & & & H6 \\
SN $\rightarrow$ LTEI & 0.117 & 0.113 & 0.112 & H7 \\
PBC $\rightarrow$ LTEI & 0.012 & 0.04 & -0.029 & H8 \\
Subjective Norms & 0.059 & 0.007 & $0.177^{* *}$ & H9 \\
SN $\rightarrow$ ATT & & & & \\
SN $\rightarrow$ PBC & $0.679^{* * *}$ & $0.674^{* * *}$ & $0.637^{* * *}$ & H10 \\
Attitude & $0.542^{* * *}$ & $0.404^{* * *}$ & $0.561^{* * *}$ & \\
ATT $\rightarrow$ PBC & & & &
\end{tabular}

Note: ${ }^{*} p<0.05 ;{ }^{* *} p<0.01 ;{ }^{* * *} p<0.001$.

Table 6. Specific indirect effects (Pakistan).

\begin{tabular}{|c|c|c|c|c|c|c|}
\hline Pakistan Sample & $\begin{array}{c}\text { Original } \\
\text { Sample (O) }\end{array}$ & $p$-Values & $\begin{array}{l}\text { Lower } \\
\text { Threshold }\end{array}$ & $\begin{array}{l}\text { Upper } \\
\text { Threshold }\end{array}$ & Hypothesis & Mediation Type \\
\hline $\mathrm{SN} \rightarrow \mathrm{ATT} \rightarrow \mathrm{STEI}$ & 0.324 & 0.000 & 0.221 & 0.44 & H11 & $\begin{array}{c}\text { Complementary (partial } \\
\text { mediation) }\end{array}$ \\
\hline $\mathrm{SN} \rightarrow \mathrm{ATT} \rightarrow \mathrm{STEI} \rightarrow \mathrm{LTEI}$ & 0.218 & 0.000 & 0.125 & 0.336 & H13 & Full mediation \\
\hline $\mathrm{SN} \rightarrow \mathrm{ATT} \rightarrow \mathrm{PBC}$ & 0.119 & 0.023 & 0.023 & 0.228 & H14 & $\begin{array}{l}\text { Complementary (partial } \\
\text { mediation) }\end{array}$ \\
\hline $\mathrm{SN} \rightarrow \mathrm{ATT} \rightarrow \mathrm{PBC} \rightarrow$ LTEI & 0.001 & 0.911 & -0.015 & 0.017 & H16 & Partial mediation \\
\hline $\begin{aligned} \mathrm{SN} & \rightarrow \mathrm{ATT} \\
\rightarrow \text { PBC } & \rightarrow \text { STEI }\end{aligned}$ & 0.005 & 0.429 & -0.004 & 0.024 & H17 & Full mediation \\
\hline $\mathrm{SN} \rightarrow \mathrm{PBC} \rightarrow \mathrm{STEI}$ & 0.027 & 0.366 & -0.025 & 0.092 & H18 & Direct-only (no mediation) \\
\hline $\mathrm{SN} \rightarrow \mathrm{PBC} \rightarrow$ LTEI & 0.003 & 0.903 & -0.047 & 0.051 & H19 & No effect (no mediation) \\
\hline $\mathrm{SN} \rightarrow \mathrm{PBC} \rightarrow \mathrm{STEI} \rightarrow \mathrm{LTEI}$ & 0.018 & 0.357 & -0.018 & 0.06 & H20 & Full mediation \\
\hline $\mathrm{ATT} \rightarrow \mathrm{STEI} \rightarrow \mathrm{LTEI}$ & 0.323 & 0.000 & 0.191 & 0.486 & H24 & $\begin{array}{l}\text { Indirect-only (full } \\
\text { mediation) }\end{array}$ \\
\hline $\mathrm{SN} \rightarrow \mathrm{STEI} \rightarrow \mathrm{LTEI}$ & 0.171 & 0.009 & 0.053 & 0.311 & H25 & $\begin{array}{l}\text { Indirect-only (full } \\
\text { mediation) }\end{array}$ \\
\hline $\mathrm{PBC} \rightarrow \mathrm{STEI} \rightarrow \mathrm{LTEI}$ & 0.045 & 0.339 & -0.047 & 0.136 & H26 & No effect (no mediation) \\
\hline
\end{tabular}


Table 7. Specific indirect effects (Vietnam).

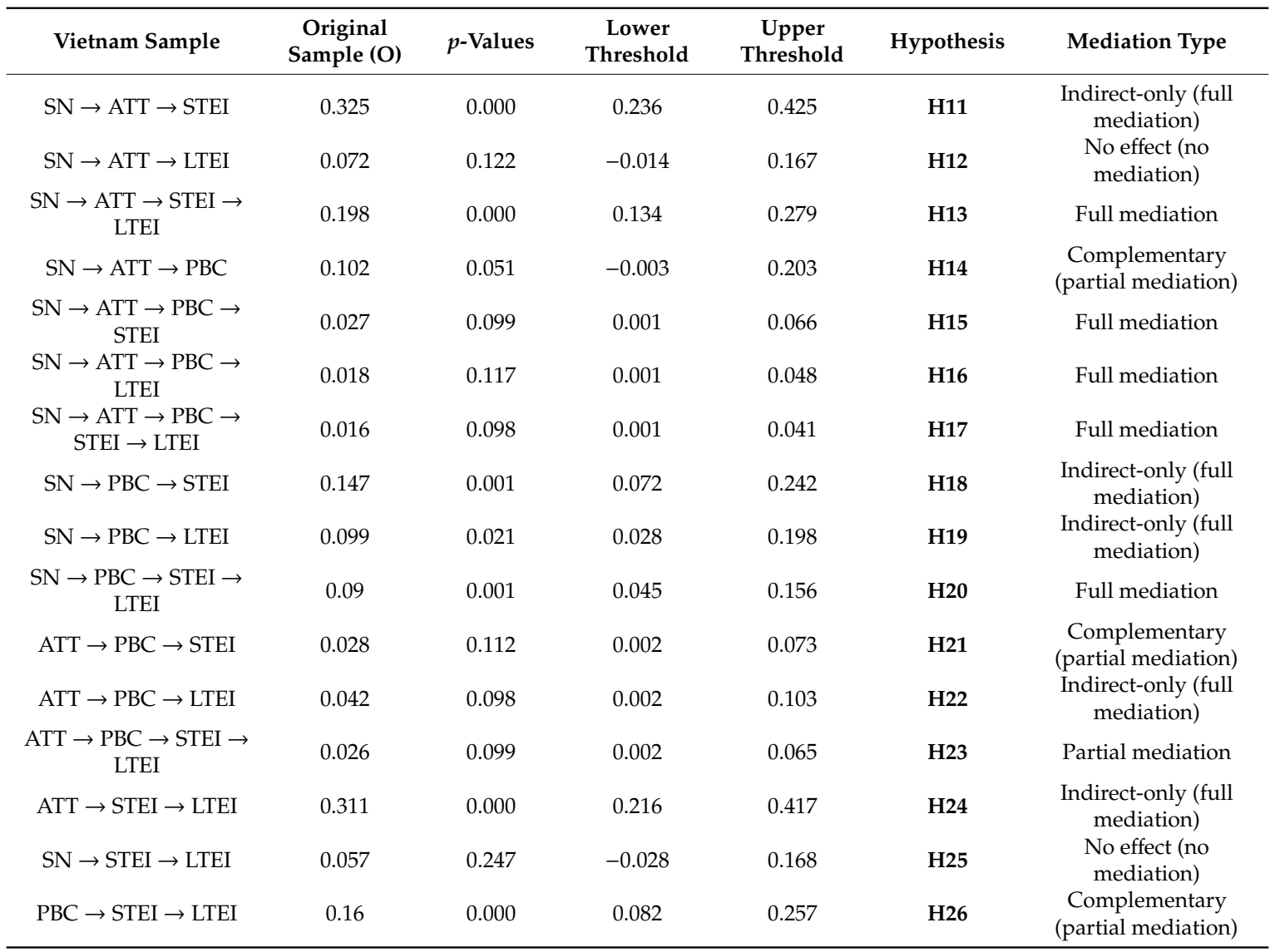

Table 8. Total indirect effects.

\begin{tabular}{ccccccc}
\hline & \multicolumn{2}{c}{ Full Sample } & \multicolumn{2}{c}{ Pakistan } & \multicolumn{2}{c}{ Vietnam } \\
& Coefficient $(\boldsymbol{\beta})$ & $\boldsymbol{p}$-Values & Coefficient $(\boldsymbol{\beta})$ & $\boldsymbol{p}$-Values & Coefficient $(\boldsymbol{\beta})$ & $\boldsymbol{p}$-Values \\
\hline $\mathrm{ATT} \rightarrow$ STEI & 0.027 & 0.029 & 0.012 & 0.418 & 0.042 & 0.098 \\
$\mathrm{ATT} \rightarrow$ LTEI & 0.343 & 0.000 & 0.332 & 0.000 & 0.365 & 0.000 \\
$\mathrm{SN} \rightarrow$ STEI & 0.432 & 0.000 & 0.359 & 0.000 & 0.499 & 0.000 \\
$\mathrm{SN} \rightarrow$ LTEI & 0.557 & 0.000 & 0.492 & 0.000 & 0.550 & 0.000 \\
$\mathrm{SN} \rightarrow$ PBC & 0.107 & 0.002 & 0.119 & 0.023 & 0.102 & 0.051 \\
$\mathrm{PBC} \rightarrow$ LTEI & 0.117 & 0.000 & 0.045 & 0.339 & 0.160 & 0.000 \\
\hline
\end{tabular}

Table 9. Compositional invariance.

\begin{tabular}{ccccc}
\hline Variables & $\begin{array}{c}\text { Configurational } \\
\text { Invariance }\end{array}$ & $\boldsymbol{c}$ & $\mathbf{5 \%}$ Quantile of $\boldsymbol{c u}$ & $\begin{array}{c}\text { Partial Measurement } \\
\text { Invariance }\end{array}$ \\
\hline LTEI & Yes & 1.000 & 1.000 & Yes \\
STEI & Yes & 0.999 & 1.000 & No \\
ATT & Yes & 1.000 & 0.999 & Yes \\
PBC & Yes & 0.999 & 0.999 & Yes \\
SN & Yes & 0.998 & 0.999 & No \\
Gender & Yes & 1.000 & 1.000 & Yes \\
\hline
\end{tabular}

Note: italic values indicate that assumptions of measurement invariance were violated between Vietnam and Pakistan. 
Table 10. Multigroup analysis (MGA).

\begin{tabular}{ccc}
\hline & Path Coefficients diff. (|Vietnam-Pakistan|) & $\boldsymbol{p}$-Value (Vietnam vs. Pakistan) \\
\hline $\mathrm{ATT} \rightarrow$ STEI & 0.030 & 0.380 \\
$\mathrm{ATT} \rightarrow$ LTEI & 0.000 & 0.498 \\
$\mathrm{ATT} \rightarrow$ PBC & 0.016 & 0.555 \\
$\mathrm{SN} \rightarrow$ STEI & 0.161 & 0.918 \\
$\mathrm{SN} \rightarrow$ LTEI & 0.070 & 0.744 \\
$\mathrm{SN} \rightarrow$ ATT & 0.037 & 0.728 \\
$\mathrm{SN} \rightarrow$ PBC & 0.157 & 0.077 \\
$\mathrm{PBC} \rightarrow$ STEI & 0.196 & 0.023 \\
$\mathrm{PBC} \rightarrow$ LTEI & 0.169 & 0.025 \\
$\mathrm{STEI} \rightarrow$ LTEI & 0.063 & 0.690 \\
Gender $\rightarrow$ STEI & 0.089 & 0.072 \\
Gender $\rightarrow$ LTEI & 0.017 & 0.382 \\
\hline
\end{tabular}

Note: significant differences are indicated by italic values.

\subsection{Mediating Analysis}

This study tested 16 hypotheses (H11 to H26) to understand the TPB dimensions (attitude and perceived behavior control) with mediating roles on entrepreneurial temporal intention; thus, short-term entrepreneurial intention was also observed under its mediation effect on long-term entrepreneurial intention. This study used indirect effect analysis to examine the mediation roles of variables. For total and specific indirect effect results, 5000 sub-samples were selected for bootstrapping to measure the effects for both countries, separately (see Tables 6 and 7). In this study, five mediation effects comply (i.e., no effect non-mediation, complementary mediation, indirect-only mediation, direct-only non-mediation and competitive mediation) [60]. The variations and types of mediation can be observed between the Pakistan and Vietnam samples by testing the direct paths' significance values and the roles of mediating variables. Partial mediation is achieved when the indirect effect and direct effect are significant. Cepeda et al.'s [102] guidelines were followed to ascertain the nature of partial mediation via checking the product with their direct and indirect effects; if the outcome is positive then ultimately complementary partial mediation is achieved. Regarding $\mathbf{H 1 1}$ to H26, the sequential mediation chain was assessed to understand how TPB dimensions have an effect on long-term entrepreneurial intention by using dimensions as serial mediators (attitude, subjective norms, perceived behavior control, short-term entrepreneurial intention) in the single and multi-sequential order to examine the effect on the path. For the Pakistan sample, the supported hypotheses are H11, H13, H14, H24, and H25. For the Vietnam sample, the supported hypotheses are H11, H13, H18, H19, H20, H24, and H26.

\subsection{Multigroup Analysis}

Multigroup analysis was performed referring to $\mathbf{H} 27$ to confirm the relationship and check the impact differences between TPB dimensions, short-term entrepreneurial intention, and long-term entrepreneurial intention across the two-country sample. In this regard, non-parametric PLS-MGA was used [5], which requires the validation of measurement invariance [98]. To validate this, the measurement invariance of composite models (MICOM) approach was used, following Henseler et al. [5]. This study confirmed and presented the configural invariance and compositional invariance. In order to check the configural and compositional invariance, data treatment was carried out to measure the models and algorithms and remained the same for Pakistan and Vietnam with a minimum sample of 5000 permutations at $5 \%$ significance. This procedure was identified and compared the original correlation score " $\mathrm{c}$ " with the permutation value "cu" from the empirical distribution. The assumption is that "if c exceeds the $5 \%$ quantile of $\mathrm{cu}$ then compositional invariance can be established". The results indicated no partial measurement invariance (see Table 9), and compositional invariance was not found. As per MICOM, when compositional invariance is not found then there is 
no need to proceed further. Table 10 presents the $p$-values below 0.05 , indicating a significant difference between Pakistan and Vietnam. The results show significance for perceived behavior control on short-term entrepreneurial intention and long-term entrepreneurial intention; however, other paths were nonsignificant in their difference between the two countries, partially supporting H27.

\section{Discussion}

This study's aim was to measure entrepreneurial intention using the temporal construal level effect and examine the relationship between TPB dimensions and entrepreneurial temporal intention (categorized into short-term and long-term entrepreneurial intention). This study examined the mediation effect of near-future intent between TPB dimensions and distant-future intent. Moreover, subjective norms were also assessed in terms of their direct effects on attitude and perceived behavior control and indirect effects on short-term and long-term entrepreneurial intention. The key findings are aligned with the TCT literature and confirm the generalizability of the results. The respondent perception clearly indicates the existence of a TCT effect in the formation of entrepreneurial intention. With reference to the TPB and TCT frameworks, the results validated the model for entrepreneurial temporal intention for Pakistan and Vietnam (see Table 11).

Table 11. Summary of results.

\begin{tabular}{|c|c|c|c|c|}
\hline Hypothesis & Path & Full Sample & Pakistan Sample & Vietnam Sample \\
\hline H1 & STEI $\rightarrow$ LTEI & Supported & Supported & Supported \\
\hline H2 & $\mathrm{ATT} \rightarrow \mathrm{STEI}$ & Supported & Supported & Supported \\
\hline H3 & $\mathrm{SN} \rightarrow \mathrm{STEI}$ & Supported & Supported & Not Supported \\
\hline H4 & $\mathrm{PBC} \rightarrow \mathrm{STEI}$ & Supported & Not Supported & Supported \\
\hline H5 & $\mathrm{ATT} \rightarrow \mathrm{LTEI}$ & Not Supported & Not Supported & Not Supported \\
\hline H6 & $\mathrm{SN} \rightarrow \mathrm{LTEI}$ & Not Supported & Not Supported & Not Supported \\
\hline H7 & $\mathrm{PBC} \rightarrow \mathrm{LTEI}$ & Not Supported & Not Supported & Supported \\
\hline H8 & $\mathrm{SN} \rightarrow \mathrm{ATT}$ & Supported & Supported & Supported \\
\hline H9 & $\mathrm{SN} \rightarrow \mathrm{PBC}$ & Supported & Supported & Supported \\
\hline H10 & $\mathrm{ATT} \rightarrow \mathrm{PBC}$ & Supported & Supported & Supported \\
\hline H11 & \multicolumn{2}{|c|}{$\mathrm{SN} \rightarrow \mathrm{ATT} \rightarrow \mathrm{STEI}$} & Mediation & Mediation \\
\hline H12 & \multicolumn{2}{|c|}{$\mathrm{SN} \rightarrow \mathrm{ATT} \rightarrow \mathrm{LTEI}$} & No Mediation & No mediation \\
\hline H13 & \multicolumn{2}{|c|}{$\mathrm{SN} \rightarrow \mathrm{ATT} \rightarrow \mathrm{STEI} \rightarrow \mathrm{LTEI}$} & Mediation & Mediation \\
\hline H14 & \multicolumn{2}{|c|}{$\mathrm{SN} \rightarrow \mathrm{ATT} \rightarrow \mathrm{PBC}$} & Mediation & Mediation \\
\hline H15 & \multicolumn{2}{|c|}{$\mathrm{SN} \rightarrow \mathrm{ATT} \rightarrow \mathrm{PBC} \rightarrow \mathrm{STEI}$} & Mediation & Mediation \\
\hline H16 & \multicolumn{2}{|c|}{$\mathrm{SN} \rightarrow \mathrm{ATT} \rightarrow \mathrm{PBC} \rightarrow \mathrm{LTEI}$} & Mediation & Mediation \\
\hline H17 & \multicolumn{2}{|c|}{$\mathrm{SN} \rightarrow \mathrm{ATT} \rightarrow \mathrm{PBC} \rightarrow \mathrm{STEI} \rightarrow \mathrm{LTEI}$} & Mediation & Mediation \\
\hline H18 & \multicolumn{2}{|c|}{$\mathrm{SN} \rightarrow \mathrm{PBC} \rightarrow \mathrm{STEI}$} & Mediation & Mediation \\
\hline H19 & \multicolumn{2}{|c|}{$\mathrm{SN} \rightarrow \mathrm{PBC} \rightarrow \mathrm{LTEI}$} & No Mediation & Mediation \\
\hline $\mathrm{H} 20$ & \multicolumn{2}{|c|}{$\mathrm{SN} \rightarrow \mathrm{PBC} \rightarrow \mathrm{STEI} \rightarrow \mathrm{LTEI}$} & Mediation & Mediation \\
\hline H21 & \multicolumn{2}{|c|}{$\mathrm{ATT} \rightarrow \mathrm{PBC} \rightarrow \mathrm{STEI}$} & Mediation & Mediation \\
\hline $\mathrm{H} 22$ & \multicolumn{2}{|c|}{$\mathrm{ATT} \rightarrow \mathrm{PBC} \rightarrow \mathrm{LTEI}$} & No Mediation & Mediation \\
\hline $\mathrm{H} 23$ & \multicolumn{2}{|c|}{$\mathrm{ATT} \rightarrow \mathrm{PBC} \rightarrow \mathrm{STEI} \rightarrow \mathrm{LTEI}$} & Mediation & Mediation \\
\hline $\mathrm{H} 24$ & \multicolumn{2}{|c|}{$\mathrm{ATT} \rightarrow \mathrm{STEI} \rightarrow$ LTEI } & Mediation & Mediation \\
\hline $\mathrm{H} 25$ & \multicolumn{2}{|c|}{$\mathrm{SN} \rightarrow \mathrm{STEI} \rightarrow \mathrm{LTEI}$} & Mediation & No mediation \\
\hline $\mathrm{H} 26$ & \multicolumn{2}{|c|}{$\mathrm{PBC} \rightarrow \mathrm{STEI} \rightarrow \mathrm{LTEI}$} & No Mediation & Mediation \\
\hline $\mathrm{H} 27$ & \multicolumn{2}{|c|}{ Difference: Pakistan vs. Vietnam } & Partially supported & Partially supported \\
\hline
\end{tabular}

There is a difference in the scores of short-term entrepreneurial intention and long-term entrepreneurial intention for both countries' samples, with long-term entrepreneurial intention higher than short-term entrepreneurial intention, which supports the TCT findings in other published studies $[2,27,32]$. The strength of short-term and long-term entrepreneurial intention depends on the country's context; TPB dimensions explained more power for Pakistan as compared to Vietnam. Another finding is the mediation role of short-term entrepreneurial intention on the causal path between TPB dimensions and long-term entrepreneurial intention, consistent with the findings of Hallam et al., 
which is specific to one predictor (i.e., perceived behavior control), although two other predictors (i.e., attitude and subjective norms), were tested in this study [2,35]. Short-term entrepreneurial intention as a part of the entrepreneurial temporal intention is driven by attitude, subjective norms, and perceived behavior control for both countries.

A proximal psychological distance is created in the near and distant future when there is time to take advice and decision support from a close group of people in relation to entrepreneurial intention, supported by the literature [21,31]. Merging TPB and TCT, it is further confirmed that short-term entrepreneurial intention mediates the effect on long-term entrepreneurial intention. An individual's plan to become an entrepreneur depends on the near and distant future based on their judgment approach; it is a mental state that defines how the action pertains to temporal construal $[2,6,35,38]$. The TCT point of view is close to TPB dimensions, which strongly influence the state of mind to take the decision to become an entrepreneur $[2,18,30,35,37,50,70,103]$. This study examined an integrated model for entrepreneurial temporal intention and confirmed the short-term entrepreneurial intention role as a mediator to have a stronger outcome of long-term entrepreneurial intention. Similarly, Hallam et al. depicted the effect of construal level on entrepreneurial intention and explained the mediating role of near-future construal towards the distant future for better understanding the causal effect on outcomes, which enables a thorough understanding of entrepreneurship models [2,104]. These findings could provide further support to refine the TPB and entrepreneurial event models, subject to demographic and geographic differences. Attitude and subjective norms play a vital role for the case of the Pakistan sample to drive the short-term entrepreneurial intention toward long-term entrepreneurial intention; however, attitude and perceived behavior control have more influence on the path of short-term entrepreneurial intention to long-term entrepreneurial intention relationship for Vietnam. The predictive power of short-term entrepreneurial intention and long-term entrepreneurial intention depends on the plausible reasons for both countries' samples (i.e., support from government, opportunities in the market, institutional support, availability of resources, and risk of doing business), which may have direct and indirect effects on business graduates' short-term and long-term entrepreneurial intentions $[25,92,105]$. This study also indicated that the perceptions of people, friends, and parents have a strong influence on an individual's attitude and perceived behavior control in order to consider a career as an entrepreneur.

This study also measured MGA results to check the differences between the paths for Pakistan and Vietnam. No significant difference was observed between the two countries; MGA analysis only indicated significant differences for short-term and long-term entrepreneurial intention, which may be due to the availability of learning opportunities to enhance their capacity to become an entrepreneur in the near and distant future.

\section{Theoretical Contribution}

The integration of TCT with TPB for measuring entrepreneurial intention depicts the psychological distance, which influences an individual's mental state and perceived behavior. The findings extracted from the structural model fit with the TPB, TCT, and entrepreneurial event models, covering the time-based thought process of an individual to respond to a particular event. It is indicated that temporal distance exists when an individual is thinking about building their entrepreneurial intention by means of abstract features or concrete details of an event. Any event that is far away in the future is most important for the purpose of planning; it is the interpretation of the upcoming situation. Meanwhile, events that are near in the future are less constructive or applicable for the purpose of pre-planning.

Any entrepreneur or businessperson will always opt for proper construal planning for the distant future to ensure its sustainability. Referring to Fishbein and Ajzen and to Liberman and Trope, the high-level intention to create a startup is initially a thought about creating a small business; thus, the intention will be formed in the presence of the combination of desirability and feasibility to jump into business operations $[1,38]$. The student will put all his/her efforts into becoming an entrepreneur, and 
for this purpose, s/he takes steps towards construal management for time and psychology. This new perspective of entrepreneurial temporal intention looks favorable, with some empirical studies having supported the hypothesis between perceptions and intentions [1,4]. A student must plan, on the temporal basis, what to do in the near and distant future. His/her interpretations or imaginations are much stronger for the distant future than for the near future.

\section{Implications}

There are certain implications for academia, institutions, and policymakers to promote a culture of entrepreneurship in both countries. The key findings indicated that students have positive attitudes towards short-term and long-term entrepreneurial intention, and willingness to continue self-employment in both countries; however, perceived behavior control needs to be established for Pakistan and subjective norms for Vietnam. Based on the results, universities should design short technical courses to develop the entrepreneurial skills of students and enable them to calculate the risk of a startup and how to mitigate it in the local market. There is an utmost need to work on the design of thinking programs, especially for Pakistani students. Policymakers should work on the entrepreneurial ecosystem in order to focus on interventions and the efficient use of existing resources for both countries. Institutions ought to facilitate students through loans, tax subsidies, and low-cost rental workplaces in the two countries, with the goal that potential new entrepreneurs can effectively execute their businesses.

\section{Limitations}

This study was limited to certain parameters, which will open new avenues for researchers. First, this study is cross-sectional. The study findings are limited to measuring short-term and long-term intent to be an entrepreneur. As a first consequence, this study cannot claim causality for predicting the intention and actual behavior of starting a business. Thus, it is necessary to conduct a longitudinal study to see the relationship and predict intention and actual behavior using a time scale $[6,43]$. Second, the sample was selected from two developing countries (Pakistan and Vietnam) and limited to university business students. In this sense, the findings have a limited scope of generalizability to developing nations and the business study discipline. Thereby, future research should replicate this study to compare developed and developing countries or, even better, compare sub-samples with multiple characteristics such as age, type and level of education, prior entrepreneurial experience, etc. This would support a better understanding of entrepreneurial temporal intention among a diverse group of respondents. Nonetheless, this study provides a strong basis for researchers in terms of the integration of TPB with TCT and the extraction of new findings, supporting entrepreneurship expatriates to take necessary actions for designing programs, which comprises the follow-up section, and helps them in turning the positive intentions and behavior of youth towards entrepreneurial activities.

\section{Conclusions}

This study provides a new perspective to measure entrepreneurial intention with time fluctuation and thus offers support in identifying potential nascent entrepreneurs based on their psychological distance in thinking and primitive action. An integrated model of entrepreneurial temporal intention based on TPB and TCT has confirmed the mediator role of short-term entrepreneurial intention between attitude, subjective norms, and perceived behavior control on the one hand, and long-term entrepreneurial intention, on the other hand, having tested the model in Pakistan and Vietnam. For both countries, long-term entrepreneurial intention is higher than short-term entrepreneurial intention, which indicates that business students need a certain amount of time to formulate intentions, arrange resources and design the business idea in the near future or develop their entrepreneurial intentions. This study indicates that entrepreneurial intention should be measured on a time scale to predict the power for the near future and distant future in order to set goals and targets for entrepreneurial activity. 
A further suggestion is to conduct longitudinal studies to test multi-factor effects on this model for entrepreneurial temporal intention.

Author Contributions: All authors contributed equally to all tasks related to performing this study and writing this article.

Funding: This research received no external funding.

Acknowledgments: The authors wish to thank the enumerators, respondents, and Muhammad Saleem for administrative support.

Conflicts of Interest: The authors declare no conflicts of interest.

\section{References}

1. Fishbein, M.; Ajzen, I. Attitudes towards objects as predictors of single and multiple behavioral criteria. Psychol. Rev. 1974, 81, 59-74. [CrossRef]

2. Hallam, C.; Zanella, G.; Dosamantes, C.A.D.; Cardenas, C. Measuring entrepreneurial intent? Temporal construal theory shows it depends on your timing. Int. J. Entrep. Behav. Res. 2016, 22, 671-697. [CrossRef]

3. Krueger, N.F. The impact of prior entrepreneurial exposure on perceptions of new venture feasibility and desirability. Entrep. Theory Pract. 1993, 18, 5-21. [CrossRef]

4. Eyal, T.; Sagristano, M.D.; Trope, Y.; Liberman, N.; Chaiken, S. When values matter: Expressing values in behavioral intentions for the near vs. distant future. J. Exp. Soc. Psychol. 2009, 45, 35-43. [CrossRef]

5. Henseler, J.; Chin, W.W. A comparison of approaches for the analysis of interaction effects between latent variables using partial least squares path modeling. Struct. Equ. Modeling 2010, 17, 82-109. [CrossRef]

6. Nasar, A.; Kamarudin, S.; Rizal, A.M.; Omar, R. A Conceptual Framework for Understanding Entrepreneurial Intention and Behavior in Near and Distant Future. In Proceedings of the 5th International Conference on New Ideas in Management, Economics and Accounting, Paris, France, 2-4 November 2018; pp. 53-60.

7. ADB-Asian Development Bank. Kyrgyz Republic: Women's Entrepreneurship Development Project; Financed by the Japan Fund for Poverty Reduction; Asian Development Bank: Bishkek, Kyrgyz Republic, 2016.

8. Hoyle, R.H. Handbook of Structural Equation Modeling; Guilford Press: New York, NY, USA, 2012.

9. Munir, H.; Jianfeng, C.; Ramzan, S. Personality traits and theory of planned behavior comparison of entrepreneurial intentions between an emerging economy and a developing country. Int. J. Entrep. Behav. Res. 2019, 25. [CrossRef]

10. Tumasjan, A.; Welpe, I.; Spörrle, M. Easy Now, Desirable Later: The Moderating Role of Temporal Distance in Opportunity Evaluation and Exploitation. Entrep. Theory Pract. 2003, 37, 859-888. [CrossRef]

11. Wang, Y.; Chen, Y.; Benitez-Amado, J. How information technology influences environmental performance: Empirical evidence from China. Int. J. Inf. Manag. 2015, 35, 160-170. [CrossRef]

12. Herrington, M.; Singer, P.K.S.; Carmona, J.; Wright, F.; Coduras, A. 2016/2017 Global Report. GEM Global Entrepreneurship Monitor; Babson College Global Entrepreneurship Research Association: Hanoi, Vietnam, 2017.

13. Carsrud, A.; Brännback, M. Entrepreneurial Motivations: What Do We Still Need to Know? J. Small Bus. Manag. 2011, 49, 9-26. [CrossRef]

14. Iakovleva, T.; Kolvereid, L.; Stephan, U. Entrepreneurial intentions in developing and developed countries. Educ. Train. 2011, 53, 353-370. [CrossRef]

15. Bird, B. Implementing entrepreneurial ideas: The case for intention. Acad. Manag. Rev. 1988, 13, 442-453. [CrossRef]

16. Krueger, N., Jr. Entrepreneurial Intentions are Dead: Long Live Entrepreneurial Intentions; Springer: New York, NY, USA, 2009; pp. 51-72.

17. Krueger, N.F., Jr.; Reilly, M.D.; Carsrud, A.L. Competing models of entrepreneurial intentions. J. Bus. Ventur. 2000, 15, 411-432. [CrossRef]

18. Fayolle, A.; Liñán, F. The future of research on entrepreneurial intentions. J. Bus. Res. 2014, 67, 663-666. [CrossRef]

19. Autio, E.; Keeley, R.H.; Klofsten, M.; Parker GG, C.; Hay, M. Entrepreneurial intent among students in Scandinavia and in the USA. Enterp. Innov. Manag. Stud. 2001, 2, 145-160. [CrossRef] 
20. Kautonen, T.; Gelderen, M.; Fink, M. Robustness of the theory of planned behavior in predicting entrepreneurial intentions and actions. Entrep. Theory Pract. 2015, 39, 655-674. [CrossRef]

21. Liñán, F.; Chen, Y.-W. Development and cross-cultural application of a specific instrument to measure entrepreneurial intentions. Entrep. Theory Pract. 2009, 33, 593-617. [CrossRef]

22. Liñán, F.; Fayolle, A. A systematic literature review on entrepreneurial intentions: Citation, thematic analyses, and research agenda. Int. Entrep. Manag. J. 2015, 11, 907-933. [CrossRef]

23. Tornikoski, E.; Maalaoui, A. Critical reflections-The Theory of Planned Behaviour: An interview with Icek Ajzen with implications for entrepreneurship research. Int. Small Bus. J. Res. Entrep. 2019, 1-15. [CrossRef]

24. Hair, J.F.; Ringle, C.M.; Sarstedt, M. PLS-SEM: Indeed a silver bullet. J. Mark. Theory Pract. 2011, 19, $139-152$. [CrossRef]

25. Marques, C.S.; Ferreira, J.J.; Gomes, D.N.; Gouveia Rodrigues, R. Entrepreneurship education: How psychological, demographic and behavioural factors predict the entrepreneurial intention. Educ. Train. 2012, 54, 657-672. [CrossRef]

26. Ainslie, G. Specious reward: A behavioral theory of impulsiveness and impulse control. Psychol. Bull. 1975, 82, 463-496. [CrossRef] [PubMed]

27. Hair, J.F.; Sarstedt, M.; Ringle, C.M.; Mena, J.A. An assessment of the use of partial least squares structural equation modeling in marketing research. J. Acad. Mark. Sci. 2012, 40, 414-433. [CrossRef]

28. Schlaegel, C.; Koenig, M. Determinants of entrepreneurial intent: A meta-analytic test and integration of competing models. Entrep. Theory Pract. 2014, 38, 291-332. [CrossRef]

29. Paul, J.; Hermel, P.; Srivatava, A. Entrepreneurial intentions-theory and evidence from Asia, America, and Europe. J. Int. Entrep. 2017, 15, 324-351. [CrossRef]

30. Zampetakis, L.A.; Kafetsios, K.; Lerakis, M.; Moustakis, V. Investigating the role of self construal in the formation of entrepreneurial intentions. Front. Psychol. 2015, 6, 1085. [CrossRef]

31. Dinc, M.S.; Budic, S. The Impact of Personal Attitude, Subjective Norm, and Perceived Behavioural Control on Entrepreneurial Intentions of Women. Eurasian J. Bus. Econ. 2016, 9, 23-35. [CrossRef]

32. Kuratko, D.F. The emergence of entrepreneurship education: Development, trends, and challenges. Entrep. Theory Pract. 2005, 29, 577-598. [CrossRef]

33. Galindo, M.Á.; Méndez, M.T. Entrepreneurship, economic growth, and innovation: Are feedback effects at work? J. Bus. Res. 2014, 67, 825-829. [CrossRef]

34. Wilson, F.; Kickul, J.; Marlino, D. Gender, entrepreneurial self-efficacy, and entrepreneurial career intentions: Implications for entrepreneurship education. Entrep. Theory Pract. 2007, 31, 387-406. [CrossRef]

35. Hallam, C.; Leffel, A.; Calvoz, R. Identification of Temporal Construal Effects on Entrepreneurial Employment Desirability in STEM Students. J. Entrep. 2015, 24, 204-222. [CrossRef]

36. Henley, A.; Contreras, F.; Espinosa, J.C.; Barbosa, D. Entrepreneurial intentions of Colombian business students: Planned behaviour, leadership skills and social capital. Int. J. Entrep. Behav. Res. 2017, 23. [CrossRef]

37. Kirkley, W.W. Entrepreneurial behaviour: The role of values. Int. J. Entrep. Behav. Res. 2016, 22, $290-328$. [CrossRef]

38. Liberman, N.; Trope, Y. The role of feasibility and desirability considerations in near and distant future decisions: A test of temporal construal theory. J. Personal. Soc. Psychol. 1998, 75, 5-18. [CrossRef]

39. Trope, Y.; Liberman, N. Temporal construal and time-dependent changes in preference. J. Personal. Soc. Psychol. 2000, 79, 876-889. [CrossRef]

40. Hoyle, R.; Kenny, D. Statistical power and test of mediation, Statistical Strategies for Small Sample Research; Sage: Thousand Oaks, CA, USA, 1999; pp. 122-139.

41. Acs, Z.J.; Szerb, L.; Lloyd, A. Global Entrepreneurship Index 2018; Global Entrepreneurship and Development Institute: Washington, DC, USA, 2017.

42. Swann, W.B., Jr.; Chang-Schneider, C.; Larsen Mcclarty, K. Do people's self-views matter? Self-concept and self-esteem in everyday life. Am. Psychol. 2007, 62, 84-94. [CrossRef]

43. Linan, F. Skill and value perceptions: How do they affect entrepreneurial intentions? Int. Entrep. Manag. J. 2008, 4, 257-272. [CrossRef]

44. Benzion, U.; Rapoport, A.; Yagil, J. Discount rates inferred from decisions: An experimental study. Manag. Sci. 1989, 35, 270-284. [CrossRef] 
45. Liñán, F.; Rodríguez-Cohard, J.; Rueda-Cantuche, J. Factors affecting entrepreneurial intention levels: A role for education. Int. Entrep. Manag. J. 2011, 7, 195-218. [CrossRef]

46. Audet, J. A longitudinal study of the entrepreneurial intentions of university students. Acad. Entrep. J. 2004, 10, 3-16.

47. Kelley, D.; Singer, S.; Herrington, M. 2015/2016 Global Report. GEM Global Entrepreneurship Monitor; Babson College, Universidad del Desarrollo, Universiti Tun Abdul Razak, Tecnológico de Monterrey; International Council for Small Business (ICSB): Wellesley, MA, USA, 2016.

48. Trope, Y.; Liberman, N. Construal-level theory of psychological distance. Psychol. Rev. 2010, 117, 440-463. [CrossRef]

49. UNDP. Unleashing Ethiopia's Entrepreneurial Spirit. 2016. Available online: http://www.et.undp.org/ content/ethiopia/en/home/operations/projects/sustainableeconomicdevelopment/project_EDP.html (accessed on 10 November 2017).

50. Gielnik, M.M.; Barabas SFrese, M.; Namatovu-Dawa, R.; Scholz, F.A.; Metzger, J.R.; Walter, T. A temporal analysis of how entrepreneurial goal intentions, positive fantasies, and action planning affect starting a new venture and when the effects wear off. J. Bus. Ventur. 2014, 29, 755-772. [CrossRef]

51. Lovallo, D.; Kahneman, D. Living with uncertainty: Attractiveness and resolution timing. J. Behav. Decis. Mak. 2000, 13, 179-190. [CrossRef]

52. Ajzen, I. From Intentions to Actions: A Theory of Planned Behavior; Springer: New York, NY, USA, 1985.

53. Abelson, R.P. Psychological status of the script concept. Am. Psychol. 1981, 36, 715-729. [CrossRef]

54. Ajzen, I. The theory of planned behavior. Organ. Behav. Hum. Decis. Process. 1991, 50, 179-211. [CrossRef]

55. Usman, B.; Yennita. Understanding the entrepreneurial intention among international students in Turkey. J. Global Entrep. Res. 2019, 9. [CrossRef]

56. Engle, R.L.; Dimitriadi, N.; Gavidia, J.V.; Schlaegel, C.; Delanoe, S.; Alvarado, I.; He, X.; Buame, S.; Wolff, B. Entrepreneurial intent: A twelve-country evaluation of Ajzen's model of planned behavior. Int. J. Entrep. Behav. Res. 2010, 16, 35-57. [CrossRef]

57. Ajzen, I. Perceived behavioral control, self-efficacy, locus of control, and the theory of planned behavior. J. Appl. Soc. Psychol. 2002, 32, 665-683. [CrossRef]

58. Ajzen, I.; Fishbein, M. The influence of attitudes on behavior. In The Handbook of Attitudes; Lawrence Erlbaum Associates: Mahwah, NJ, USA, 2005; pp. 173-221.

59. Fayolle, A.; Gailly, B. The impact of entrepreneurship education on entrepreneurial attitudes and intention: Hysteresis and persistence. J. Small Bus. Manag. 2015, 53, 75-93. [CrossRef]

60. Zhao, H.; Seibert, S.E.; Hills, G.E. The mediating role of self-efficacy in the development of entrepreneurial intentions. J. Appl. Psychol. 2005, 90, 1265-1272. [CrossRef]

61. Townsend, T.G.; Grange, C.; Belgrave, F.Z.; Wilson, K.D.; Fitzgerald, A.; Owens, K. Understanding HIV risk among African American adolescents: The role of Africentric values and ethnic identity in the theory of planned behavior. Humboldt J. Soc. Relat. 2006, 30, 89-120.

62. Liñán, F.; Urbano, D.; Guerrero, M. Regional variations in entrepreneurial cognitions: Start-up intentions of university students in Spain. Entrep. Reg. Dev. 2011, 23, 187-215. [CrossRef]

63. Kautonen, T.; Van Gelderen, M.; Tornikoski, E.T. Predicting entrepreneurial behaviour: A test of the theory of planned behavior. Appl. Econ. 2013, 45, 697-707. [CrossRef]

64. Roy, R.; Akhtar, F.; Das, N. Entrepreneurial intention among science \& technology students in India: Extending the theory of planned behavior. Int. Entrep. Manag. J. 2017, 13, 1013-1041.

65. Shinnar, R.S.; Giacomin, O.; Janssen, F. Entrepreneurial perceptions and intentions: The role of gender and culture. Entrep. Theory Pract. 2012, 36, 465-493. [CrossRef]

66. Cardon, M.S.; Kirk, C.P. Entrepreneurial passion as mediator of the self-efficacy to persistence relationship. Entrep. Theory Pract. 2015, 39, 1027-1050. [CrossRef]

67. Chowdhury, M.S.; Shamsudin, F.M.; Ismail, H.C. Exploring potential women entrepreneurs among international women students: The effects of the theory of planned behavior on their intention. World Appl. Sci. J. 2012, 17, 651-657.

68. Kristiansen, S.; Indarti, N. Entrepreneurial Intention Among Indonesian and Norwegian Students. J. Enterprising Cult. 2004, 12, 55-78. [CrossRef]

69. Etzioni, A. Entrepreneurship, adaptation and legitimation: A macro-behavioral perspective. J. Econ. Behav. Organ. 1987, 8, 175-189. [CrossRef] 
70. Arrighetti, A.; Caricati, L.; Landini, F.; Monacelli, N. Entrepreneurial intention in the time of crisis: A field study. Int. J. Entrep. Behav. Res. 2016, 22, 835-859. [CrossRef]

71. Kolvereid, L.; Isaksen, E. New business start-up and subsequent entry into self-employment. J. Bus. Ventur. 2006, 21, 866-885. [CrossRef]

72. Tkachev, A.; Kolvereid, L. Self-employment intentions among Russian students. Entrep. Reg. Dev. 1999, 11, 269-280. [CrossRef]

73. Sobel, R.S. Entrepreneurship, Library of Economics and Liberty. 2008. Available online: www.econlib.org/ library/Enc/Entrepreneurship.html (accessed on 15 October 2019).

74. Bagozzi, R.P.; Baumgartner, J.; Yi, Y. An investigation into the role of intentions as mediators of the attitude-behavior relationship. J. Econ. Psychol. 1989, 10, 35-62. [CrossRef]

75. Shapero, A.; Sokol, L. The Social Dimension of Entrepreneurship; Pretince-Hall: Englewood Cliffs, NJ, USA, 1982; pp. 72-90.

76. Shapero, A. The displaced, uncomfortable entrepreneur. Psychol. Today 1975, 9, 83-88.

77. Shapero, A. Some social dimensions of entrepreneurship; The Ohio State University: Columbus, OH, USA, 1980.

78. Seligman, M. Learned Optimism; AA Knopf: New York, NY, USA, 1991.

79. Bandura, A. Social Foundations of Thought and Action: A Social Cognitive Theory; Prentice-Hall, Inc.: Englewood Cliffs, NJ, USA, 1986.

80. Bandura, A. Perceived self-efficacy in cognitive development and functioning. Educ. Psychol. 1993, 28, 117-148. [CrossRef]

81. Sarstedt, M.; Ringle, C.M.; Smith, D.; Reams, R.; Hair, J.F., Jr. Partial least squares structural equation modeling (PLS-SEM): A useful tool for family business researchers. J. Fam. Bus. Strategy 2014, 5, 105-115. [CrossRef]

82. Huan, L.M.; Hang, P.T.T.; Hoang, N.; Trang, T.K.; Anh, D.V.P.; Nga, M.D.T. Global Entrepreneurship Monitor Vietnam Report 2017/2018. Vietnam Chamber of Commerce and Industry-VCCI; Global Entrepreneurship Research Association-GERA: Hanoi, Vietnam, 2018.

83. IMF-International Monetary Fund. Fiscal Policies for Innovation and Growth. 2016. Available online: https://www.imf.org/ \{\}/media/Websites/IMF/imported-flagshipissues/external/pubs/ft/fm/2016/ 01/pdf/_fmc2pdf.ashx (accessed on 15 September 2019).

84. Qureshi, M.S.; Mian, S.A. Global entrepreneurship monitor Pakistan report 2012. In Global report, GEM 2012; Institute of Business Administration: Karachi, Pakistan, 2012; Available online: https:/gemconsortium.org/ economy-profiles/pakistan (accessed on 15 September 2019).

85. Liberman, N.; Sagristano, M.D.; Trope, Y. The effect of temporal distance on level of mental construal. J. Exp. Soc. Psychol. 2002, 38, 523-534. [CrossRef]

86. Bae, T.J.; Qian, S.; Miao, C.; Fiet, J.O. The relationship between entrepreneurship education and entrepreneurial intentions: A meta-analytic review. Entrep. Theory Pract. 2014, 38, 217-254. [CrossRef]

87. Pruett, M.; Shinnar, R.; Toney, B.; Llopis, F.; Fox, J. Explaining entrepreneurial intentions of university students: A cross-cultural study. Int. J. Entrep. Behav. Res. 2009, 15, 571-594. [CrossRef]

88. Faul, F.; Erdfelder, E.; Buchner, A.; Lang, A.-G. Statistical power analyses using G*Power 3.1: Tests for correlation and regression analyses. Behav. Res. Methods 2009, 41, 1149-1160. [CrossRef] [PubMed]

89. WESO-World Employment and Social Outlook; Trends; International Labour Office: Geneva, Switzerland, 2017.

90. Mueller, S.L. Gender gaps in potential for entrepreneurship across countries and cultures. J. Dev. Entrep. 2004, 9, 199-220.

91. Lewis, P. The quest for invisibility: Female entrepreneurs and the masculine norm of entrepreneurship. Gend. Work Organ. 2006, 13, 453-469. [CrossRef]

92. Arshad, M.; Farooq, O.; Sultana, N.; Farooq, M. Determinants of individuals' entrepreneurial intentions: A gender-comparative study. Career Dev. Int. 2016, 21, 318-339. [CrossRef]

93. Keele, L.; Tingley, D.; Yamamoto, T. Identifying mechanisms behind policy interventions via causal mediation analysis. J. Policy Anal. Manag. 2015, 34, 937-963. [CrossRef]

94. Heuer, A.; Liñán, F. Testing alternative measures of subjective norms in entrepreneurial intention models. Int. J. Entrep. Small Bus. 2013, 19, 35. [CrossRef]

95. Sarstedt, M.; Henseler, J.; Ringle, C.M. Multigroup analysis in partial least squares (PLS) path modeling: Alternative methods and empirical results. Adv. Int. Mark. 2011, 22, 195-218. 
96. Chin, W.W. The partial least squares approach to structural equation modeling. Mod. Methods Bus. Res. 1998, 295, 295-336.

97. Henseler, J.; Ringle, C.M.; Sinkovics, R.R. The use of partial least squares path modeling in international marketing. In New Challenges to International Marketing; Advances in International Marketing; Emerald Group Publishing Limited: Bingley, UK, 2009; pp. 277-319. [CrossRef]

98. Hair, J.F.; Black, W.C.; Babin, B.J.; Anderson, R.E. Multivariate Data Analysis, 7th ed.; Prentice Hall: Upper Saddle River, NJ, USA, 2010.

99. Hair, J.F., Jr.; Lukas, B. Marketing Research, 2nd ed.; McGraw-Hill Education: North Ryde, NSW, Australia, 2014.

100. Peterman, N.E.; Kennedy, J. Enterprise education: Influencing students' perceptions of entrepreneurship. Entrep. Theory Pract. 2003, 28, 129-144. [CrossRef]

101. Hair, J.F.; Hult, G.T.M.; Ringle, C.M.; Sarstedt, M. A Primer on Partial Least Squares Structural Equation Modeling (PLS-SEM); Sage: Thousand Oaks, CA, USA, 2016.

102. Cepeda, G.; Nitzl, C.; Roldán, J.L. Mediation analyses in partial least squares structural equation modeling: Guidelines and empirical examples. In Partial Least Squares Path Modeling: Basic Concepts, Methodological Issues and Applications; Latan, H., Noonan, R., Eds.; Springer: Heidelberg, Germany, 2018.

103. Valliere, D. Multidimensional entrepreneurial intent: An internationally validated measurement approach. Int. J. Entrep. Behav. Res. 2017, 23, 59-77. [CrossRef]

104. Baron, R.M.; Kenny, D.A. The moderator-mediator variable distinction in social psychological research: Conceptual, strategic, and statistical considerations. J. Personal. Soc. Psychol. 1986, 51, 1173-1182. [CrossRef]

105. Podsakoff, P.M.; MacKenzie, S.B.; Lee, J.-Y.; Podsakoff, N.P. Common method biases in behavioral research: A critical review of the literature and recommended remedies. J. Appl. Psychol. 2003, 88, 879-903. [CrossRef]

(C) 2019 by the authors. Licensee MDPI, Basel, Switzerland. This article is an open access article distributed under the terms and conditions of the Creative Commons Attribution (CC BY) license (http://creativecommons.org/licenses/by/4.0/). 